\title{
Scale Dependence of Waviness and Unevenness of Natural Rock Joints through Fractal Analysis
}

\author{
Yingchun Li $\mathbb{D}^{1}{ }^{1}$ Shengyue Sun, ${ }^{1}$ and Hongwei Yang ${ }^{2}$ \\ ${ }^{1}$ State Key Laboratory of Coastal and Offshore Engineering, Dalian University of Technology, Dalian, China 116024 \\ ${ }^{2}$ Institute for Geology, Mineralogy and Geophysics, Ruhr University Bochum, Bochum, Germany D-44780 \\ Correspondence should be addressed to Yingchun Li; yingchun_li@dlut.edu.cn
}

Received 19 May 2020; Revised 7 July 2020; Accepted 29 July 2020; Published 25 August 2020

Academic Editor: Qian Yin

Copyright ( 2020 Yingchun Li et al. This is an open access article distributed under the Creative Commons Attribution License, which permits unrestricted use, distribution, and reproduction in any medium, provided the original work is properly cited.

\begin{abstract}
The scale dependence of surface roughness is critical in characterising the hydromechanical properties of field-scale rock joints but is still not well understood, particularly when different orders of roughness are considered. We experimentally reveal the scale dependence of two-order roughness, i.e., waviness and unevenness through fractal parameters using the triangular prism surface area method (TPM). The surfaces of three natural joints of granite with the same dimension of $1000 \mathrm{~mm} \times 1000 \mathrm{~mm}$ are digitised using a 3D laser scanner at three different measurement resolutions. Waviness and unevenness are quantitatively separated by considering the area variation of joint surface as grid size changes. The corresponding fractal dimensions of waviness and unevenness in sampling window sizes ranging from $100 \mathrm{~mm} \times 100 \mathrm{~mm}$ to $1000 \mathrm{~mm} \times 1000 \mathrm{~mm}$ at an interval of $100 \mathrm{~mm} \times 100 \mathrm{~mm}$ are determined. We find that both the fractal dimensions of waviness and unevenness vary as the window size increases. No obvious stationarity threshold has been found for the three rock joint samples, indicating the surface roughness of natural rock joints should be quantified at the scale of the rock mass in the field.
\end{abstract}

\section{Introduction}

Rock masses contain a large body of joints. The mechanical and hydraulic behaviours of rock joints highly affect the hydromechanical properties of rock masses. Due to geological processes, rock joints with natural surfaces occur over a broad scale from millimeters to kilometers. Accurate description of joint roughness at the relevant scale is crucial for predicting the hydromechanical coupling of the rock mass.

The surfaces of natural rock joints exhibit varying degrees of roughness. Roughness refers to the inherent unevenness and waviness of a rock joint surface relative to its mean plane [1]. Initially, waviness and unevenness represent large-scale undulations observed in the field and small-scale roughness sampled in the laboratory, respectively $[2,3]$. Large-scale undulations dominate joint dilatancy since they are too large to be sheared off, and small-scale roughness affects joint shear strength as it is usually damaged under shear. The surface of a laboratory-sized rock joint also exhibits two-order asperities, i.e., first-order waviness and second-order uneven- ness [4-8]. Waviness with comparatively larger wavelength and amplitude primarily contributes to dilation, whereas unevenness of a smaller asperity size is sheared and damaged, providing shear resistance to the shear movement. That is to say, a rock joint surface is characterised by two-order roughness at various scales [9]. Although numerous empirical and statistical approaches have been proposed to quantify the roughness of rock joints [10-15], they have rarely taken into account the two-order roughness of a joint surface that plays distinct roles in the mechanical and hydraulic behaviours of rock joints $[7,16,17]$.

The roughness of a natural rock joint surface depends on the scale of examination, which is referred to as scale effect. Bandis et al. [18] reported that the value of $J R C$ (joint roughness coefficient) decreased as the rock joint size increased, i.e., negative scale effect. On the other hand, conflicting results including positive and no scale effects have been observed [19-22]. By examining the morphological characteristics of the surface roughness of a large-scale rock joint replica $(1000 \mathrm{~mm} \times 1000 \mathrm{~mm})$, Fardin et al. [23] also stated that there was a stationarity threshold beyond which 


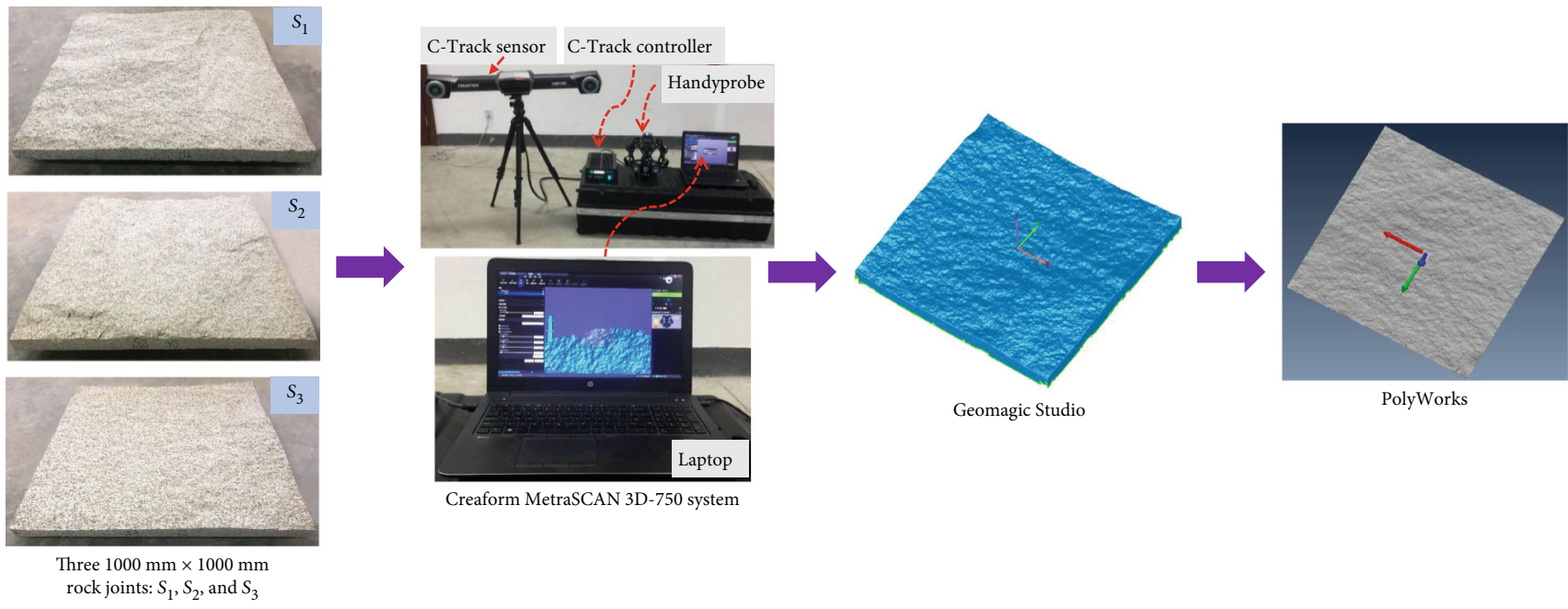

Figure 1: Digitisation of a $1000 \mathrm{~mm} \times 1000 \mathrm{~mm}$ rock joint surface.

the scale dependency of surface roughness vanished, i.e., the roughness remained unvaried once the scale exceeded the size of the stationarity threshold. Due to these controversial findings, the nature of how scale affects the surface roughness remains enigmatic.

Fractal theory $[24,25]$ has been successfully applied to characterise the roughness of rock joints at varying scales. Many approaches to estimate the fractal dimension of a rock joint profile have been proposed, including ruler length [26], box counting [27], variogram [28, 29], spectral [30, 31], roughness length $[9,23,32,33]$, and line scaling [34]. The triangular prism surface area method (TPM) [35-37], project covering method (PCM) [38-40], and cubic covering method (CCM) [41] are shown to be applicable for determining the fractal geometry of a three-dimensional joint surface. However, few of them have considered the individual fractal dimensions of waviness and unevenness since a universal single value was commonly assumed.

In this paper, we examine the fractal characteristics of waviness and unevenness of three natural granite rock joints dimensioned up to $1000 \mathrm{~mm} \times 1000 \mathrm{~mm}$. We find that eachorder roughness possesses individual fractal dimension at varying sizes from $100 \mathrm{~mm} \times 100 \mathrm{~mm}$ to $1000 \mathrm{~mm} \times 1000$ $\mathrm{mm}$. The waviness and unevenness of a rock joint surface are separated by considering the surface area variation as grid size changes. The fractal dimension of each-order roughness is calculated using TPM (triangular prism surface area method). Evident scale dependency of fractal dimension of each-order roughness has been observed. However, the stationarity threshold of the joint surface roughness is possibly absent.

\section{Data Acquisition}

We scanned and reconstructed the three-dimensional surfaces of three natural granite joints 70 (labeled $S_{1}, S_{2}$, and $S_{3}$, respectively) sourced from a quarry in Fujian Province, China (Figure 1).

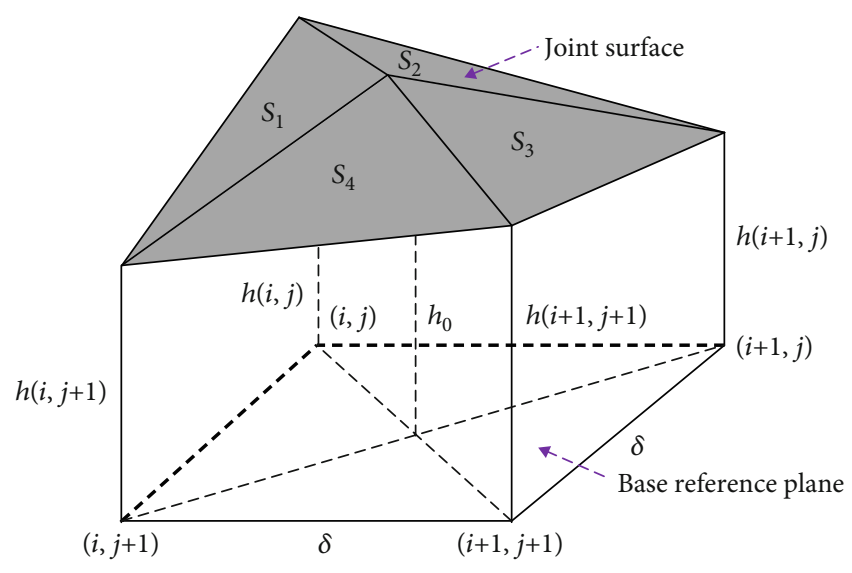

FIgURE 2: Illustration of the triangular prism surface area method (after Clarke [35]). $\delta$ is the grid size, $S_{1}, S_{2}, S_{3}$, and $S_{4}$ represent the areas of four triangles; $(i, j),(i, j+1)$, and $(i+1, j+1)$ are, respectively, the coordinates of the four points of the triangular prism, $h(0)$ denotes the elevation at the center of the grid cell, and $h(i, j), h(i+1, j), h(i, j+1)$, and $h(i+1, j+1)$ are the elevations of the four points, respectively.

The dimension of each rock joint surface was $1000 \mathrm{~mm}$ $\times 1000 \mathrm{~mm}$. The rock joint surfaces were initially covered by a very thin layer of dust. We carefully cleaned the dust with wipes to avoid damaging the surface roughness. Visual observation suggested that the granite joints are light gray and unweathered.

When the rock joint surfaces were naturally dried in the laboratory, a Creaform MetraSCAN 3D 750 system was employed to digitise the joint surface at three measurement resolutions with point spacings being $0.5 \mathrm{~mm}, 1.0 \mathrm{~mm}$, and $2.0 \mathrm{~mm}$, respectively. The optical scanning system consists of a HandyPROBE for scanning, a C-Track sensor to locate the position of the HandyPROBE, a C-Track controller for data acquisition, and a laptop for image processing and display (Figure 1). It ideally can acquire the topographic information of an object up to several meters at a minimum point spacing of $0.05 \mathrm{~mm}$. During data acquisition, we 


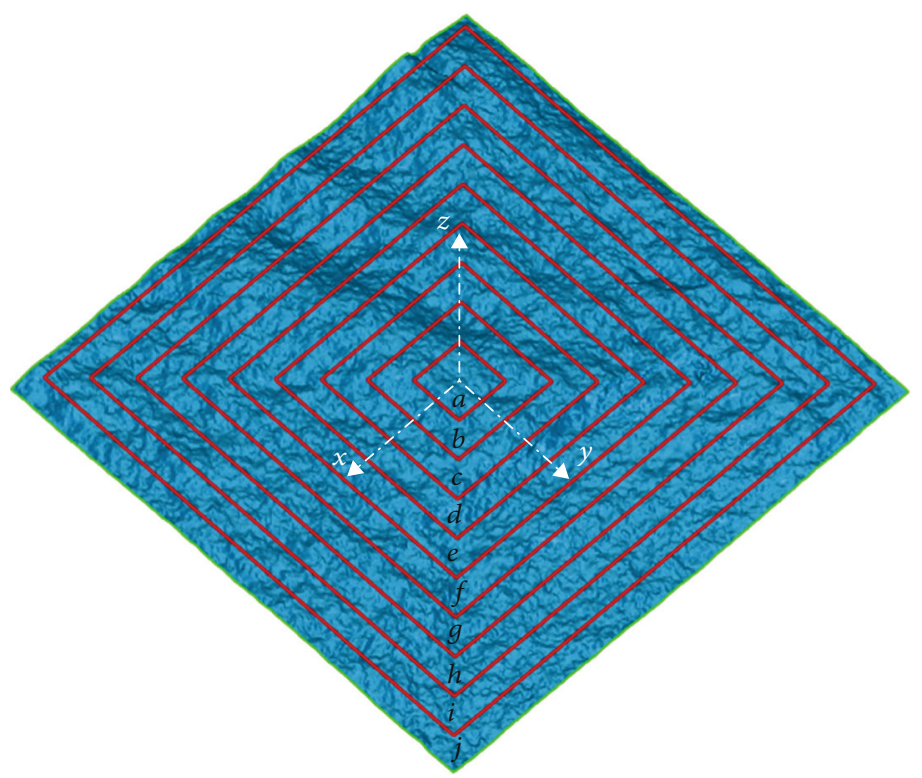

FiguRE 3: Illustration of the square windows of different sizes from $a=100 \mathrm{~mm} \times 100 \mathrm{~mm}$ to $j=1000 \mathrm{~mm} \times 1000 \mathrm{~mm}$ chosen from the central part of a rock joint surface.

scanned the rock joint surface region by region very slowly and carefully to fully capture the morphological properties of the rock joint surfaces. The digitised surface of the rock joint was visualised simultaneously over scanning through the laptop monitor, which ensured that each surface was thoroughly reconstructed without small empty areas remained. We attempted to obtain a more detailed joint surface at the point spacing of $0.2 \mathrm{~mm}$ but failed due to memory limitation of the laptop. The graphic processing software, Geomagic Studio, was employed to coordinate the data acquired through the scanner. The graphic processing software, PolyWorks, converted the format of the data imported from Geomagic Studio to the format that is readable by the data processing software, MATLAB.

\section{Fractal Dimensions of Waviness and Unevenness}

We used the well-established triangular prism surface area method (TPM) [35, 37] to estimate the fractal dimensions of waviness and unevenness. The principle of TPM is that the true surface area of a joint surface is measurable once the heights of all points on the joint surface above a base reference plane are established. For a square grid with a side length of $\delta$ (Figure 2), the elevation at the center of the grid cell $\left(h_{0}\right)$ is determined by the elevations of its four points:

$$
h_{0}=\frac{1}{4}[h(i, j)+h(i, j+1)+h(i+1, j)+h(i+1, j+1)] \text {, }
$$

where $h(i, j), h(i, j+1), h(i+1, j)$, and $h(i+1, j+1)$ are the elevations of the four points, respectively (Figure 2 ).
The area of one of the triangles, $S_{1}$, is as follows:

$$
S_{1}=\sqrt{l_{1}\left(l_{1}-a_{1}\right)\left(l_{1}-b_{1}\right)\left(l_{1}-c_{1}\right)}
$$

where $l_{1}=1 / 2\left(a_{1}+b_{1}+c_{1}\right)$,

$$
\begin{aligned}
& a_{1}=\sqrt{[h(i, j)-h(i, j+1)]^{2}+\delta^{2}}, \\
& b_{1}=\sqrt{\left[h(i, j)-h_{0}\right]^{2}+\frac{1}{2} \delta^{2}}, \\
& c_{1}=\sqrt{\left[h(i, j+1)-h_{0}\right]^{2}+\frac{1}{2} \delta^{2}} .
\end{aligned}
$$

Similarly, the areas of the other three triangles, i.e., $S_{2}, S_{3}$, and $S_{4}$, are calculated, respectively. The true area of a joint surface in a given grid cell sized of $\delta \times \delta$ is as follows:

$$
S_{i, j}=S_{1}+S_{2}+S_{3}+S_{4}
$$

The joint surface area is as follows:

$$
S(\delta)=\sum_{i, j=1}^{N(\delta)} S_{i, j}
$$

where $N(\delta)$ denotes the number of total grid cells. The joint surface area is a function of grid size $(\delta)$ by [37]:

$$
S(\delta)=A \delta^{2-D},
$$

where $D$ is the fractal dimension of a joint surface, and $A$ is a coefficient. Note that the original approach of Clarke [35] estimated the fractal dimension $(D)$ through the relationship 


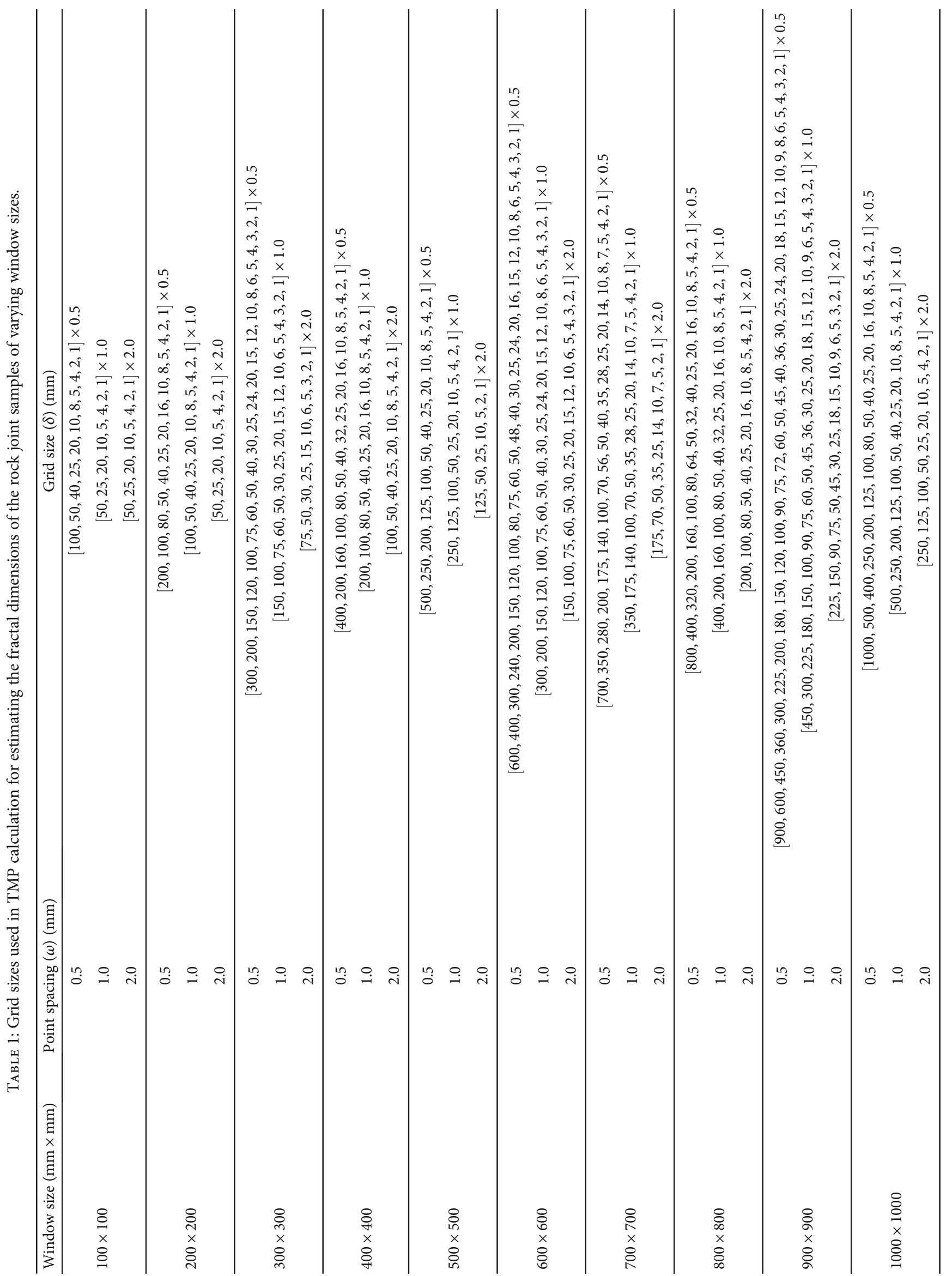


between joint surface area $S(\delta)$ and grid size square $\left(\delta^{2}\right)$, i.e., $S(\delta)=A\left(\delta^{2}\right)^{2-D}$. However, Equation (6) using grid size is proven to be mathematically correct and experimentally reliable $[36,37,42]$ as the use of the grid size square underestimated fractal dimension [43].

To double-logarithmise Equation (6), we have:

$$
\ln (S(\delta))=\ln A+(2-D) \ln (\delta)
$$

where $D$ and $A$ are estimated from the slope and intercept of the $\ln (S(\delta))-\ln (\delta)$ plot, respectively.

To investigate the scale dependency of surface roughness, the fractal dimensions of waviness and unevenness of the three rock joint samples at varying window sizes from 100 $\mathrm{mm} \times 100 \mathrm{~mm}$ to $1000 \mathrm{~mm} \times 1000 \mathrm{~mm}$ are estimated (Figure 3). The square window of different sizes is selected from the central part of a rock joint surface. We first plot the relationship between $\ln (S(\delta))$ and $\ln (\delta)$ based on Equations (1), (2), (4), (5), (6), and (7). The joint surface area is computed at varying grid sizes through Equation (5). Table 1 shows the grid size used in calculating the joint surface area at varying window sizes of different measurement resolutions from $100 \mathrm{~mm} \times 100 \mathrm{~mm}$ to $1000 \mathrm{~mm} \times 1000 \mathrm{~mm}$ at the interval of $100 \mathrm{~mm} \times 100 \mathrm{~mm}$. As illustrated in Figure 4, the principle of grid size determination is to ensure that the side length of the sampling window is divisible by the grid size $(\delta)$ that is a multiple of the point spacing. Figure 5 demonstrates the double-logarithmic relationship between surface area $(\ln (S(\delta)))$ and grid size $(\ln (\delta))$ of the three rock joint samples at the dimension of $800 \mathrm{~mm} \times 800 \mathrm{~mm}$ under the resolution of point spacing at $1.0 \mathrm{~mm}$. The surface areas of the three joint samples are calculated through TPM with each grid size ranging from $1 \mathrm{~mm}$ to $400 \mathrm{~mm}$, i.e., $\delta=$ $[400,200,160,100,80,50,40,32,25,20,16,10,8,5,4,2,1] \times$ $1 \mathrm{~mm}$. Waviness and unevenness are separated by considering the area variation of a joint surface at varying grid sizes. Specifically, as the grid size decreases, the joint surface area increases to approximately the real surface area. When the grid size exceeds $30 \mathrm{~mm}$, the slope of the $\ln (S(\delta))-\ln (\delta)$ plot decreases remarkably. Under this circumstance, the joint surface area is primarily contributed by waviness, whereas the surface area of unevenness is excluded. For all the three rock joint samples, the slopes of the $\ln (S(\delta))-\ln$ $(\delta)$ curves vary noticeably at the grid size of $30 \mathrm{~mm}$ at which waviness and unevenness are separated. Figure 6 illustrates the decomposition of a rock joint surface into profiles of waviness and unevenness.

The unevenness is acquired by subtracting the waviness from the whole joint surface. The fractal dimensions of waviness $\left(D_{w}\right)$ and unevenness $\left(D_{u}\right)$ of a rock joint surface are determined from the two slopes of each bilinear curve, respectively (Figure 4). Actually, similar bilinearity of the $\ln$ $(S(\delta))-\ln (\delta)$ plot of tension-induced rock joint surfaces has been reported by several researchers $[40,41]$. They found that the rock joint surface has nonuniversal fractal dimensions, depending on the measurement scale. However, the nature of the two-order fractal dimensions that are explained above was not unveiled by the authors.

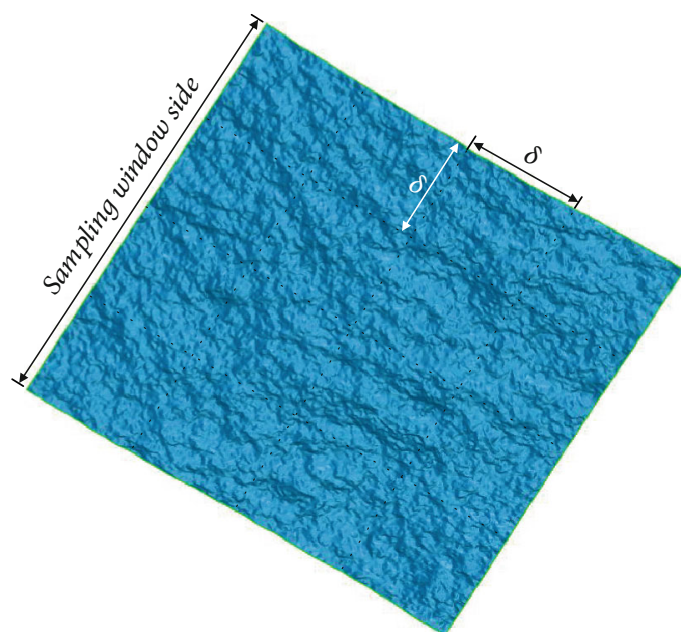

FIgURE 4: Illustration of grid size $(\delta)$ determination in TPM calculation. The rationale is that the side length of sampling window is divisible by the grid size $(\delta)$ that is a multiple of the point spacing.

\section{Results}

4.1. Scale Effect. Figure 7 shows that the fractal dimensions of two-order roughness are scale-dependent for the three rock joint samples digitised at three measurement resolutions. Tables 2-4 list the fractal dimensions of waviness and unevenness of rock joint samples $S_{1}$ to $S_{3}$ at varying sizes, respectively. For joint sample $S_{1}$ at a fixed point spacing, the fractal dimension of waviness is the highest at the sampling window of $100 \mathrm{~mm} \times 100 \mathrm{~mm}$, followed by a decrease once the sampling window grows to $200 \mathrm{~mm} \times 200 \mathrm{~mm}$. As the side length of the sampling window increases to $400 \mathrm{~mm}$, the fractal dimension of waviness peaks with a value smaller than that at the sampling window of $100 \mathrm{~mm} \times 100$ $\mathrm{mm}$. When the side length of the sampling window increases from $400 \mathrm{~mm}$ to $1000 \mathrm{~mm}$, the fractal dimension of waviness generally decreases with slight fluctuations at the side lengths of $700 \mathrm{~mm}$ and $900 \mathrm{~mm}$. The fractal dimension of unevenness of joint sample $S_{1}$ at a certain point spacing, however, is the smallest at the window size of $100 \mathrm{~mm} \times 100 \mathrm{~mm}$. The fractal dimension of unevenness rises continuously to a peak value as the sampling window size increases to 400 $\mathrm{mm} \times 400 \mathrm{~mm}$, followed by an overall decrease as the sampling window size is increased to the maximum value of $1000 \mathrm{~mm} \times 1000 \mathrm{~mm}$.

For rock joint sample $S_{2}$ under a certain measurement resolution, the fractal dimension of waviness fluctuates slightly as the window side length increases from $100 \mathrm{~mm}$ to $400 \mathrm{~mm}$, preceding a gradual decrease when the window size grows to $700 \mathrm{~mm} \times 700 \mathrm{~mm}$. As the sampling window size increases from $700 \mathrm{~mm} \times 700 \mathrm{~mm}$ to $100 \mathrm{~mm} \times 1000 \mathrm{~mm}$, the fractal dimension of waviness increases marginally. The fractal dimension of unevenness seemingly exhibits no general tendency. The magnitude of the fractal dimension of unevenness roughly levels off with several unremarkable fluctuations at different sampling window sizes. 


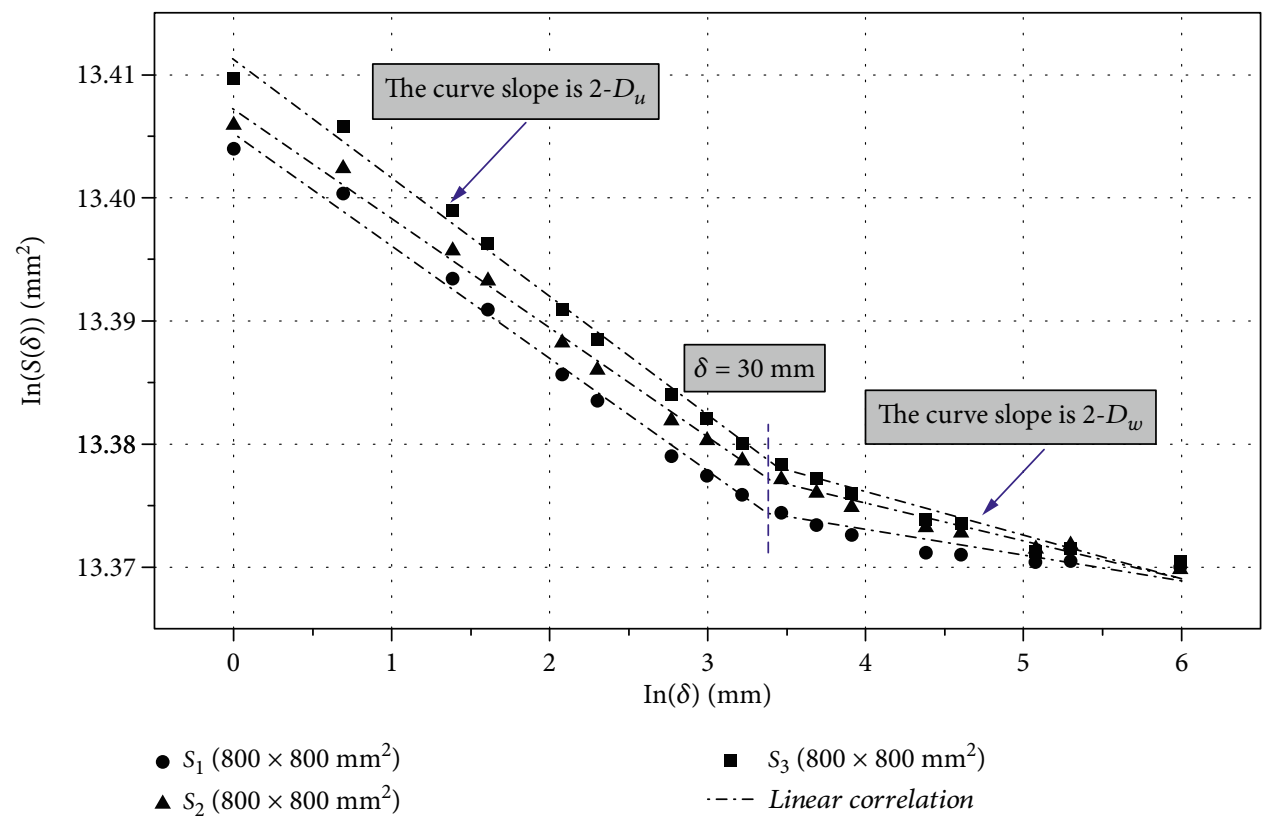

Figure 5: Double-logarithmic relationship between joint surface area $(S(\delta))$ and grid size $(\delta) . D_{w}$ and $D_{u}$ denote the fractal dimensions of waviness and unevenness, respectively.
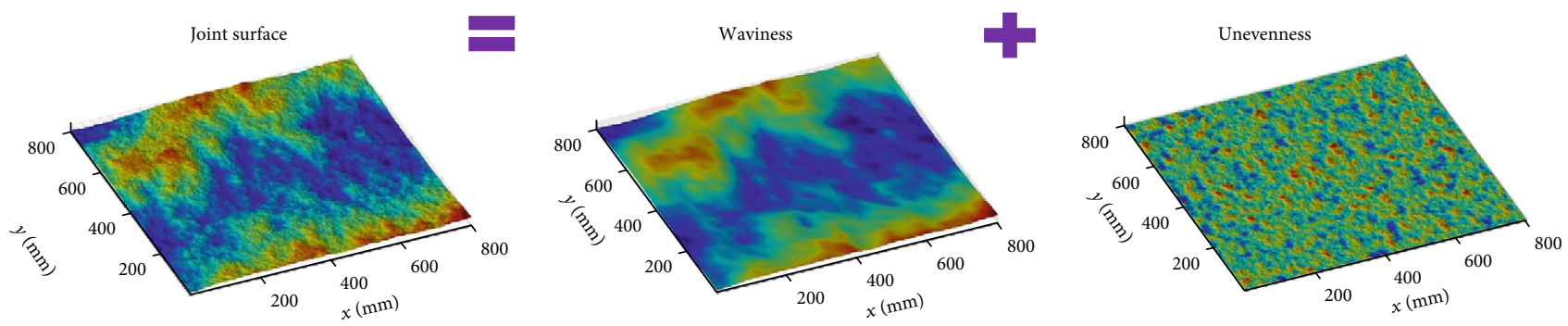

FIGURE 6: Decomposition of a rock joint surface into waviness and unevenness.

For rock joint sample $S_{3}$ at a fixed point spacing, the fractal dimension of waviness is maximum at the window size of $100 \mathrm{~mm} \times 100 \mathrm{~mm}$ and then predominantly declines as the window side length increases to $1000 \mathrm{~mm}$ with slight fluctuations. The variation of fractal dimension of unevenness resembles that of rock joint sample $S_{2}$ without noticeable trend.

To quantify the variation of fractal dimensions of waviness and unevenness as the window size is enlarged, the percent error relative to the value of window size of 100 $\mathrm{mm} \times 100 \mathrm{~mm}$ is calculated as follows:

$$
\delta_{i}=\frac{\left|D_{i}-D_{100}\right|}{D_{100}} \times 100 \%,
$$

where $\delta_{i}$ and $D_{i}$ represent the percent error and fractal dimension of waviness or unevenness at a window size between $200 \mathrm{~mm} \times 200 \mathrm{~mm}$ to $1000 \mathrm{~mm} \times 1000 \mathrm{~mm}$, respectively. $D_{100}$ is the fractal dimension of waviness or unevenness at the window size of $100 \mathrm{~mm} \times 100 \mathrm{~mm}$.
Figure 8 presents the percent errors of waviness and unevenness of the three rock joint samples at window sizes from $200 \mathrm{~mm} \times 200 \mathrm{~mm}$ to $1000 \mathrm{~mm} \times 1000 \mathrm{~mm}$ at three measurement resolutions. Generally, the effect of window size on the fractal dimension of waviness is more pronounced than that of unevenness. Particularly for rock joint samples $S$ ${ }_{2}$ and $S_{3}$, the percent errors of fractal dimension of unevenness are lower than $0.1 \%$. The variations of fractal dimensions of both waviness and unevenness of rock joint sample $S_{1}$ are overall larger than those of rock joint samples $S_{2}$ and $S_{3}$ at the same window size and resolution. For rock joint sample $S_{1}$, the percent errors of the fractal dimension of waviness at varying window sizes under the resolution of $1.0 \mathrm{~mm}$ are unanimously the highest, and $2.0 \mathrm{~mm}$ the lowest. The percent error of the fractal dimension of unevenness under the resolution of $0.5 \mathrm{~mm}$ is the highest, and $2.0 \mathrm{~mm}$ the lowest except at the window size of $400 \mathrm{~mm}$ $\times 400 \mathrm{~mm}$ where the percent error of the fractal dimension of unevenness under the point spacing of $1.0 \mathrm{~mm}$ is marginally smaller than that under $2.0 \mathrm{~mm}$. For rock joint sample $S_{2}$, the percent errors of the fractal dimension of waviness at varying window sizes under the resolution of 


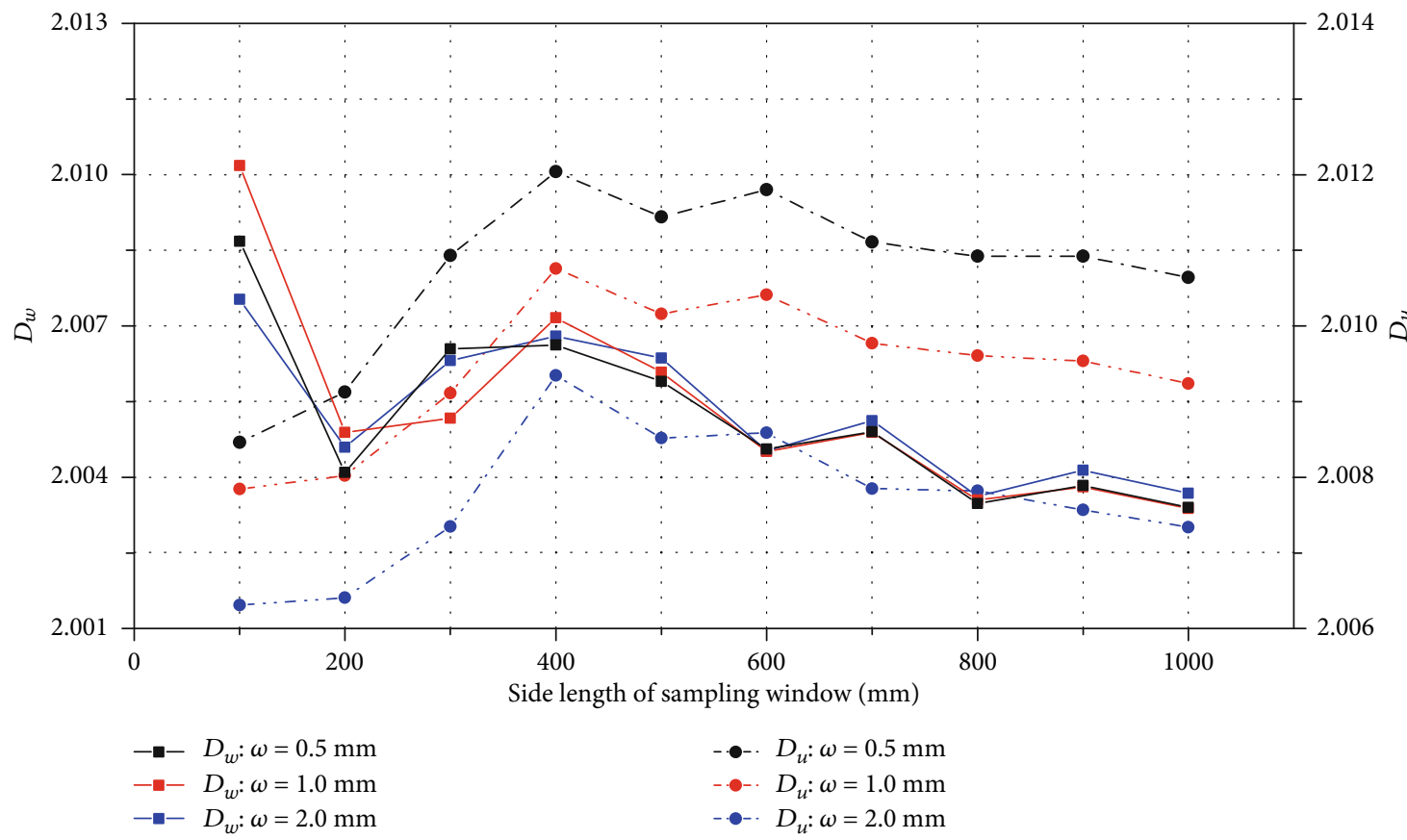

(a) Two-order fractal dimensions of surface roughness of joint sample $S_{1}$

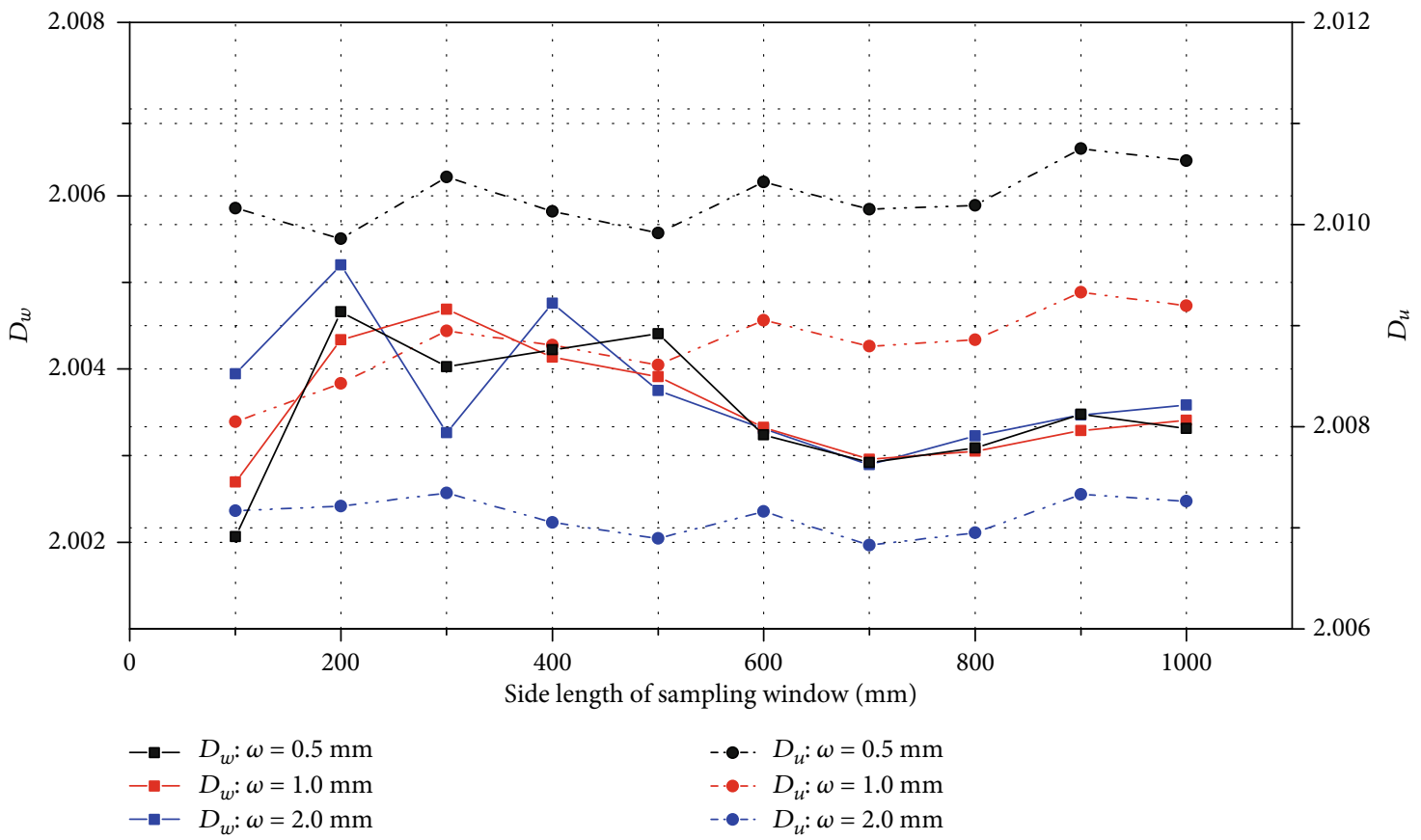

(b) Two-order fractal dimensions of surface roughness of joint sample $S_{2}$

FIgUre 7: Continued. 


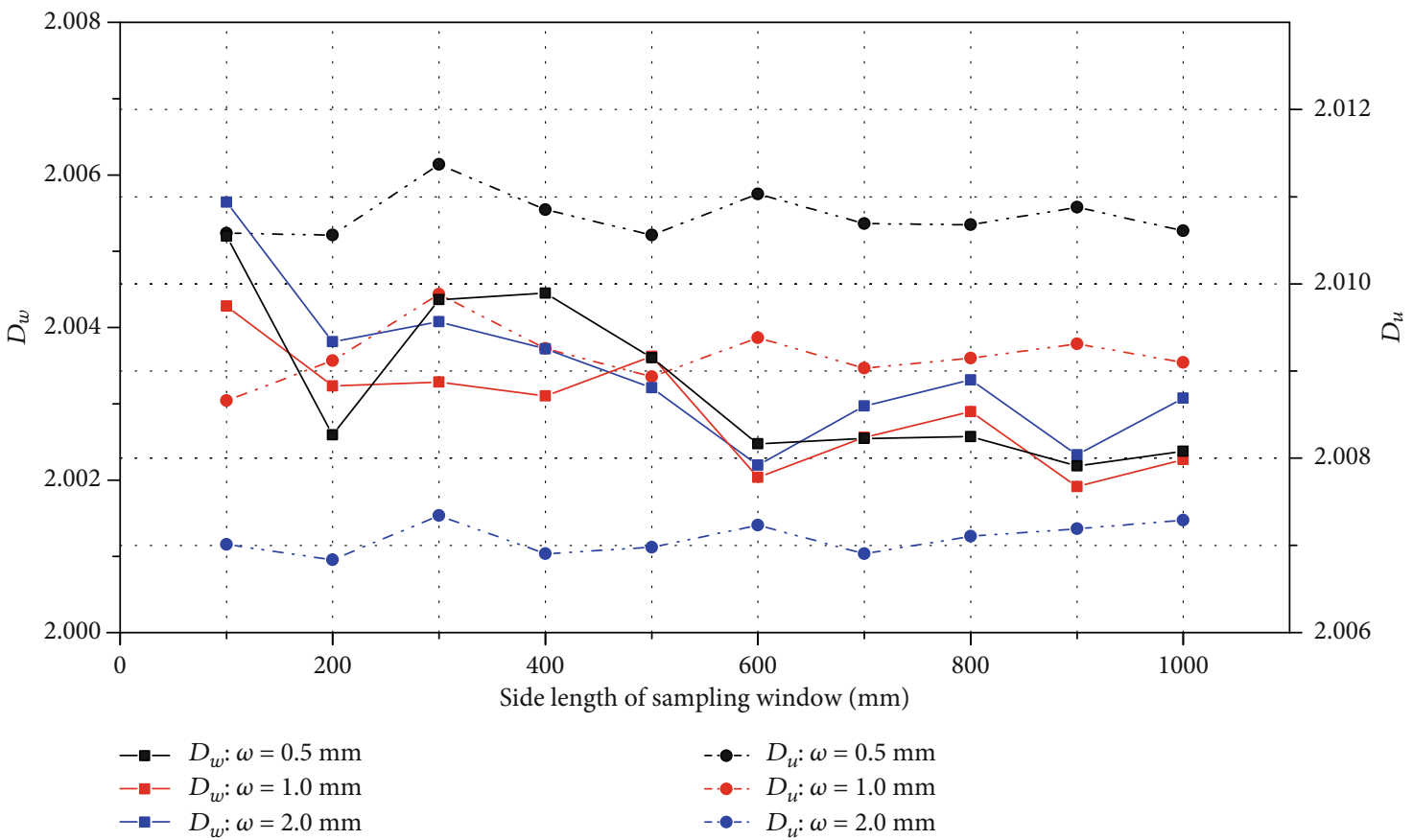

(c) Two-order fractal dimensions of surface roughness of joint sample $S_{3}$

FIGURE 7: Fractal dimensions of waviness and unevenness of three rock joints of three resolutions at varying window sizes. $D_{w}$ and $D_{u}$ are fractal dimensions of waviness and unevenness, respectively. $\omega$ denotes the point spacing.

TABLE 2: Fractal dimensions of waviness and unevenness of rock joint sample $S_{1}$ at varying window sizes.

\begin{tabular}{|c|c|c|c|c|c|c|c|c|c|c|c|}
\hline \multirow{2}{*}{$\begin{array}{l}\text { Point } \\
\text { spacing } \\
(\mathrm{mm})\end{array}$} & \multirow{2}{*}{$\begin{array}{c}\text { Fractal } \\
\text { estimation }\end{array}$} & \multicolumn{10}{|c|}{ Window size $(\mathrm{mm} \times \mathrm{mm})$} \\
\hline & & $100 \times 100$ & $200 \times 200$ & $300 \times 300$ & $400 \times 400$ & $500 \times 500$ & $600 \times 600$ & $700 \times 700$ & $800 \times 800$ & $900 \times 900$ & $1000 \times 1000$ \\
\hline \multirow{6}{*}{0.5} & $D_{w}$ & 2.008677 & 2.004098 & 2.006542 & 2.006624 & 2.005897 & 2.004557 & 2.004899 & 2.00348 & 2.003838 & 2.0034 \\
\hline & $A_{w}$ & 10360 & 40920 & 93180 & 166200 & 258300 & 369600 & 503400 & 653400 & 827600 & 964300 \\
\hline & $R_{w}^{2}$ & 0.999 & 0.9116 & 0.9621 & 0.9671 & 0.9561 & 0.9599 & 0.9694 & 0.9179 & 0.9543 & 0.9056 \\
\hline & $D_{u}$ & 2.008463 & 2.009124 & 2.01093 & 2.01204 & 2.01144 & 2.0118 & 2.01111 & 2.01092 & 2.01092 & 2.01064 \\
\hline & $A_{u}$ & 10350 & 41610 & 94500 & 169400 & 263500 & 378800 & 513900 & 669900 & 846800 & 988400 \\
\hline & $R_{u}^{2}$ & 0.9906 & 0.9873 & 0.9893 & 0.9907 & 0.9904 & 0.9909 & 0.9908 & 0.9906 & 0.9783 & 0.9886 \\
\hline \multirow{6}{*}{1.0} & $D_{w}$ & 2.01018 & 2.004889 & 2.00517 & 2.007159 & 2.006078 & 2.004509 & 2.004889 & 2.003546 & 2.003809 & 2.003378 \\
\hline & $A_{w}$ & 10420 & 41060 & 92560 & 166600 & 258600 & 369500 & 503400 & 653600 & 827500 & 964500 \\
\hline & $R_{w}^{2}$ & 0.999 & 0.9365 & 0.9264 & 0.9818 & 0.9686 & 0.9641 & 0.982 & 0.9367 & 0.9589 & 0.9172 \\
\hline & $D_{u}$ & 2.007841 & 2.008021 & 2.009109 & 2.01076 & 2.01016 & 2.01041 & 2.009771 & 2.009609 & 2.009538 & 2.009236 \\
\hline & $A_{u}$ & 10330 & 41500 & 93710 & 168800 & 262500 & 377300 & 51190 & 667400 & 843900 & 984600 \\
\hline & $R_{w}^{2}$ & 0.9944 & 0.9943 & 0.9916 & 0.9931 & 0.9931 & 0.993 & 0.9941 & 0.994 & 0.9934 & 0.9921 \\
\hline \multirow{6}{*}{2.0} & $D_{w}$ & 2.007528 & 2.004591 & 2.006311 & 2.006796 & 2.00636 & 2.004521 & 2.005116 & 2.003627 & 2.004135 & 2.003681 \\
\hline & $A_{w}$ & 10320 & 41000 & 93040 & 166300 & 259000 & 369600 & 503800 & 653800 & 828500 & 966100 \\
\hline & $R_{w}^{2}$ & 0.999 & 0.945 & 0.9412 & 0.9766 & 0.9518 & 0.9546 & 0.9688 & 0.9164 & 0.9636 & 0.9025 \\
\hline & $D_{u}$ & 2.006311 & 2.006409 & 2.007347 & 2.009343 & 2.008571 & 2.008585 & 2.007849 & 2.007821 & 2.007567 & 2.00734 \\
\hline & $A_{u}$ & 10280 & 41280 & 93470 & 168000 & 261000 & 375200 & 508800 & 663700 & 838800 & 978600 \\
\hline & $R_{u}^{2}$ & 0.9879 & 0.9894 & 0.9891 & 0.9843 & 0.993 & 0.9857 & 0.9948 & 0.9878 & 0.9903 & 0.9905 \\
\hline
\end{tabular}

Note: $D_{w}$ and $D_{u}$ are fractal dimensions of waviness and unevenness, respectively. $A_{w}$ and $A_{u}$ are the coefficients during linear correlations for estimating $D_{w}$ and $D_{u}$, respectively. $R_{w}^{2}$ and $R_{u}^{2}$ represent the coefficients of determination during linear correlations for estimating $D_{w}$ and $D_{u}$, respectively. 
TABLE 3: Fractal dimensions of waviness and unevenness of rock joint sample $S_{2}$ at varying window sizes.

\begin{tabular}{|c|c|c|c|c|c|c|c|c|c|c|c|}
\hline \multirow{2}{*}{$\begin{array}{l}\text { Point } \\
\text { spacing } \\
(\mathrm{mm})\end{array}$} & \multirow{2}{*}{$\begin{array}{c}\text { Fractal } \\
\text { estimation }\end{array}$} & \multicolumn{10}{|c|}{ Window size $(\mathrm{mm} \times \mathrm{mm})$} \\
\hline & & $100 \times 100$ & $200 \times 200$ & $300 \times 300$ & $400 \times 400$ & $500 \times 500$ & $600 \times 600$ & $700 \times 700$ & $800 \times 800$ & $900 \times 9000$ & $1000 \times 1000$ \\
\hline \multirow{6}{*}{0.5} & $D_{w}$ & 2.002065 & 2.004658 & 2.004025 & 2.004222 & 2.004405 & 2.003238 & 2.002918 & 2.003086 & 2.003475 & 2.003312 \\
\hline & $A_{w}$ & 10140 & 40920 & 91850 & 163500 & 25590 & 366900 & 49870 & 651800 & 82650 & 963700 \\
\hline & $R_{w}^{2}$ & 0.999 & 0.971 & 0.9343 & 0.9728 & 0.9756 & 0.981 & 0.9442 & 0.9449 & 0.9664 & 0.9589 \\
\hline & $D_{u}$ & 2.01016 & 2.009858 & 2.01047 & 2.01013 & 2.009915 & 2.01042 & 2.01015 & 2.01075 & 2.01075 & 2.01063 \\
\hline & $A_{u}$ & 10410 & 41620 & 93790 & 166600 & 26070 & 375600 & 2.01015 & 667200 & 84620 & 987600 \\
\hline & $R_{u}^{2}$ & 0.9876 & 0.9893 & 0.9893 & 0.9886 & 0.9858 & 0.989 & 51090 & 0.9893 & 0.9719 & 0.9882 \\
\hline \multirow{6}{*}{1.0} & $D_{w}$ & 2.002696 & 2.004337 & 2.004687 & 2.004136 & 2.003912 & 2.003324 & 2.002957 & 2.003051 & 2.003287 & 2.003409 \\
\hline & $A_{w}$ & 10150 & 40860 & 92090 & 163400 & 25550 & 367100 & 49890 & 651700 & 82590 & 964300 \\
\hline & $R_{w}^{2}$ & 0.999 & 0.9652 & 0.9654 & 0.954 & 0.9623 & 0.9777 & 0.9399 & 0.9465 & 0.9604 & 0.9578 \\
\hline & $D_{u}$ & 2.008048 & 2.008427 & 2.008947 & 2.008806 & 2.008611 & 2.009051 & 2.008796 & 2.008859 & 2.009329 & 2.009198 \\
\hline & $A_{u}$ & 10350 & 41430 & 93410 & 166000 & 25980 & 374200 & 50900 & 664700 & 84320 & 983800 \\
\hline & $R_{w}^{2}$ & 0.9849 & 0.9919 & 0.9902 & 0.9924 & 0.9907 & 0.9928 & 0.9934 & 0.9932 & 0.9921 & 0.9908 \\
\hline \multirow{6}{*}{2.0} & $D_{w}$ & 2.003945 & 2.005202 & 2.003265 & 2.004757 & 2.003571 & 2.003308 & 2.002896 & 2.003225 & 2.00347 & 2.003585 \\
\hline & $A_{w}$ & 10190 & 41000 & 91580 & 163900 & 25520 & 367000 & 49870 & 652300 & 82640 & 956300 \\
\hline & $R_{w}^{2}$ & 0.999 & 0.9499 & 0.9362 & 0.9418 & 0.9384 & 0.9771 & 0.9547 & 0.9387 & 0.9538 & 0.9417 \\
\hline & $D_{u}$ & 2.00717 & 2.007215 & 2.007344 & 2.007052 & 2.006896 & 2.00716 & 2.006828 & 2.006952 & 2.00733 & 2.007264 \\
\hline & $A_{u}$ & 10310 & 41290 & 92930 & 165100 & 25810 & 372100 & 50590 & 660800 & 83810 & 977700 \\
\hline & $R_{u}^{2}$ & 0.9799 & 0.9895 & 0.9885 & 0.9919 & 0.9927 & 0.9886 & 0.9927 & 0.9909 & 0.9894 & 0.9899 \\
\hline
\end{tabular}

Note: $D_{w}$ and $D_{u}$ are fractal dimensions of waviness and unevenness, respectively. $A_{w}$ and $A_{u}$ are the coefficients during linear correlation for estimating $D_{w}$ and $D_{u}$, respectively. $R_{w}^{2}$ and $R_{u}^{2}$ represent the coefficients of determination during linear correlations for estimating $D_{w}$ and $D_{u}$, respectively.

$0.5 \mathrm{~mm}$ generally are the highest, and $2.0 \mathrm{~mm}$ the lowest except at the window side lengths of $300 \mathrm{~mm}$ and $800 \mathrm{~mm}$. The percent errors of the fractal dimension of unevenness of rock joint samples $S_{2}$ and $S_{3}$ at the resolution of $1.0 \mathrm{~mm}$ are the highest.

Figures 7 and 8 show that the fractal dimension of eachorder roughness varies from 2.001 to 2.014, and the percent errors of fractal dimensions of waviness and unevenness of the three rock joint samples are numerically small, which are less than $1 \%$. One may draw the conclusion that the scale effect of the fractal dimensions of waviness and unevenness could be neglected. Actually, the low values of percent errors result from the low values of the fractal dimensions (Figure 7) which are common for the rough surfaces of naturally formed rock joints [39, 41, 44]. Many studies reported that the fractal geometry of the surface roughness of threedimensional rock joints is slightly larger than 2.0 [38-41]. Zhou and Xie [41] showed that the fractal dimensions of the surface roughness of tension-induced rock joints of varying degrees of roughness are all smaller than 2.07. Similarly, several rock joints collected from in situ also exhibited surface roughness of fractal dimensions around 2.05, whereas the JRC (joint roughness coefficient) values [10] of these joint surfaces reached as high as 14.0 [38]. That is to say, a naturally surfaced rock joint possesses a fractal dimension varying in a very narrow band. A small variation in fractal dimension likely leads to noticeable change of surface roughness $[26,45]$.

The low values of the percent errors of fractal dimensions do not necessarily mean that the variation of surface roughness is negligible as window size change, because the widely used indicators of surface roughness such as JRC and asperity slope can be mathematically related with fractal dimension through certain relationships $[45,46]$. These relationships commonly involve scaling coefficients of quite high values [45].

To illustrate the effect of fractal dimension variation on the joint roughness change, the well-established relationship linking fractal dimension $(D)$ and $J R C$ is employed [26]:

$$
J R C=-0.87804+37.7844\left(\frac{D-1}{0.015}\right)-16.9304\left(\frac{D-1}{0.015}\right)^{2}
$$

Equation (9) was originally proposed to estimate JRC through the fractal dimension $(D)$ of a two-dimensional joint profile. Since the relationship between $J R C$ and the fractal dimension $(D)$ of a three-dimensional joint surface is unavailable, the above formulation is directly adopted by extending the two-dimension to three-dimension by replacing $(D-1)$ with $(D-2)$. Additionally, our purpose is not to 
TABLE 4: Fractal dimensions of waviness and unevenness of rock joint sample $S_{3}$ at varying window sizes.

\begin{tabular}{|c|c|c|c|c|c|c|c|c|c|c|c|}
\hline \multirow{2}{*}{$\begin{array}{l}\text { Point } \\
\text { spacing } \\
(\mathrm{mm})\end{array}$} & \multirow{2}{*}{$\begin{array}{c}\text { Fractal } \\
\text { estimation }\end{array}$} & \multicolumn{10}{|c|}{ Window size $(\mathrm{mm} \times \mathrm{mm})$} \\
\hline & & $100 \times 100$ & $200 \times 200$ & $300 \times 300$ & $400 \times 400$ & $500 \times 500$ & $600 \times 600$ & $700 \times 700$ & $800 \times 800$ & $900 \times 900$ & $1000 \times 1000$ \\
\hline \multirow{6}{*}{0.5} & $D_{w}$ & 2.005199 & 2.00259 & 2.004366 & 2.00445 & 2.003602 & 2.002477 & 2.002543 & 2.00257 & 2.002184 & 2.002377 \\
\hline & $A_{w}$ & 10120 & 40950 & 91870 & 163500 & 254600 & 364700 & 496700 & 649000 & 820100 & 957800 \\
\hline & $R_{w}^{2}$ & 0.999 & 0.9685 & 0.9246 & 0.9634 & 0.9582 & 0.9101 & 0.9252 & 0.9042 & 0.9158 & 0.9196 \\
\hline & $D_{u}$ & 2.01058 & 2.01056 & 2.01137 & 2.01085 & 2.01056 & 2.01103 & 2.01069 & 2.01068 & 2.01088 & 2.01061 \\
\hline & $A_{u}$ & 10390 & 41580 & 93880 & 166900 & 260600 & 375100 & 510300 & 666400 & 843300 & 984100 \\
\hline & $R_{u}^{2}$ & 0.9739 & 0.9859 & 0.9883 & 0.9864 & 0.9846 & 0.9883 & 0.9897 & 0.9894 & 0.9704 & 0.9858 \\
\hline \multirow{6}{*}{1.0} & $D_{w}$ & 2.004282 & 2.003235 & 2.003286 & 2.003104 & 2.003623 & 2.002034 & 2.002557 & 2.002896 & 2.001913 & 2.002271 \\
\hline & $A_{w}$ & 10180 & 40600 & 91430 & 162600 & 25460 & 364100 & 496800 & 647700 & 819100 & 955500 \\
\hline & $R_{w}^{2}$ & 0.999 & 0.9092 & 0.9133 & 0.9028 & 0.9321 & 0.9013 & 0.9124 & 0.929 & 0.9102 & 0.9049 \\
\hline & $D_{u}$ & 2.00866 & 2.009118 & 2.009879 & 2.009258 & 2.008936 & 2.009383 & 2.009035 & 2.009148 & 2.009312 & 2.0091 \\
\hline & $A_{u}$ & 10340 & 41410 & 93450 & 166100 & 259300 & 373400 & 507900 & 663500 & 839900 & 979800 \\
\hline & $R_{w}^{2}$ & 0.9831 & 0.9887 & 0.9899 & 0.9893 & 0.99 & 0.9927 & 0.9929 & 0.9927 & 0.9915 & 0.9901 \\
\hline \multirow{6}{*}{2.0} & $D_{w}$ & 2.00564 & 2.003815 & 2.004073 & 2.00372 & 2.00321 & 2.002192 & 2.002969 & 2.003313 & 2.002331 & 2.003075 \\
\hline & $A_{w}$ & 10230 & 40690 & 91750 & 163100 & 254300 & 364400 & 497600 & 648500 & 820600 & 963300 \\
\hline & $R_{w}^{2}$ & 0.999 & 0.9013 & 0.9109 & 0.9069 & 0.9065 & 0.9091 & 0.929 & 0.9184 & 0.9347 & 0.9201 \\
\hline & $D_{u}$ & 2.007011 & 2.006835 & 2.007341 & 2.006906 & 2.006979 & 2.007231 & 2.006903 & 2.007105 & 2.007191 & 2.007291 \\
\hline & $A_{u}$ & 10280 & 41120 & 92820 & 164900 & 257700 & 371000 & 504600 & 659400 & 834700 & 977300 \\
\hline & $R_{u}^{2}$ & 0.99 & 0.989 & 0.9918 & 0.9922 & 0.9922 & 0.991 & 0.9906 & 0.9924 & 0.9907 & 0.9921 \\
\hline
\end{tabular}

Note: $D_{w}$ and $D_{u}$ are fractal dimensions of waviness and unevenness, respectively. $A_{w}$ and $A_{u}$ are the coefficients during linear correlation for estimating $D_{w}$ and $D_{u}$, respectively. $R_{w}^{2}$ and $R_{u}^{2}$ represent the coefficients of determination during linear correlations for estimating $D_{w}$ and $D_{u}$, respectively.

quantify $J R C$ through fractal dimension $(D)$, but to demonstrate the significant joint roughness variation due to the small change of fractal dimension. Considering the twoorder roughness separation, $J R C$ values of waviness and unevenness $\left(J R C_{w}\right.$ and $\left.J R C_{u}\right)$ are, respectively,

$$
\begin{gathered}
J R C_{w}=-0.87804+37.7844\left(\frac{D_{w}-2}{0.015}\right)-16.9304\left(\frac{D_{w}-2}{0.015}\right)^{2}, \\
J R C_{u}=-0.87804+37.7844\left(\frac{D_{u}-2}{0.015}\right)-16.9304\left(\frac{D_{u}-2}{0.015}\right)^{2} .
\end{gathered}
$$

Figure 9 shows the effect of window size on the percent errors of $J R C$ values of waviness and unevenness $\left(J R C_{w}\right.$ and $J R C_{u}$ ) of the three rock joint samples of different measurement resolutions. For joint samples $S_{1}$ to $S_{3}, J R C$ values of waviness $\left(J R C_{w}\right)$ exhibit strong scale dependency without general trend. The maximum percent errors of $J R C_{w}$ of joint samples $S_{1}, S_{2}$, and $S_{3}$ occur on window sizes of $1000 \mathrm{~mm} \times$ $1000 \mathrm{~mm}, \quad 200 \mathrm{~mm} \times 200 \mathrm{~mm}$, and $600 \mathrm{~mm} \times 600 \mathrm{~mm}$, respectively, suggesting the randomness of the scale effect. Additionally, similar to the fractal dimension, the effect of window size on $J R C_{w}$ is much more pronounced than on $J$ $R C_{u}$. For joint sample $S_{1}$, the percent errors of $J R C_{w}$ are generally appreciably larger than those of $J R C_{u}$ with a maximum value smaller than $40 \%$. For joint samples $S_{2}$ and $S_{3}$, the percent errors of $J R C_{w}$ can be as high as $130 \%$, whereas the percent errors of $J R C_{u}$ are all lower than $15 \%$ with a majority less than $10 \%$, which indicates that the scale effect of $J R C_{u}$ may be insignificant.

4.2. Effect of Measurement Resolution. We digitised the surface of each rock joint sample using three different resolutions. Figure 10 shows the percent errors of the fractal dimensions of waviness and unevenness of the three rock joint samples at resolutions of $1.0 \mathrm{~mm}$ and $2.0 \mathrm{~mm}$, respectively, relative to the point spacing of $0.5 \mathrm{~mm}$. Both the fractal dimensions of waviness and unevenness are dependent of measurement resolution. The fractal dimension of unevenness is much more sensitive to the measurement resolution compared with that of waviness. For all the three samples, the fractal dimension of unevenness is the largest at the highest resolution and vice versa. The percent error of fractal dimension of unevenness under the point spacing of $2.0 \mathrm{~mm}$ is roughly two times that under point spacing of $0.5 \mathrm{~mm}$. Nevertheless, the fractal dimension of waviness of all the three samples is seemingly unaffected by the resolution. In this study, waviness are asperities in wavelength longer than $30 \mathrm{~mm}$ that is substantially greater than the prescribed point spacings. The fractal dimension of waviness is theoretically independent on the resolution of point spacing less than $30 \mathrm{~mm}$. In many cases, the difference of fractal 


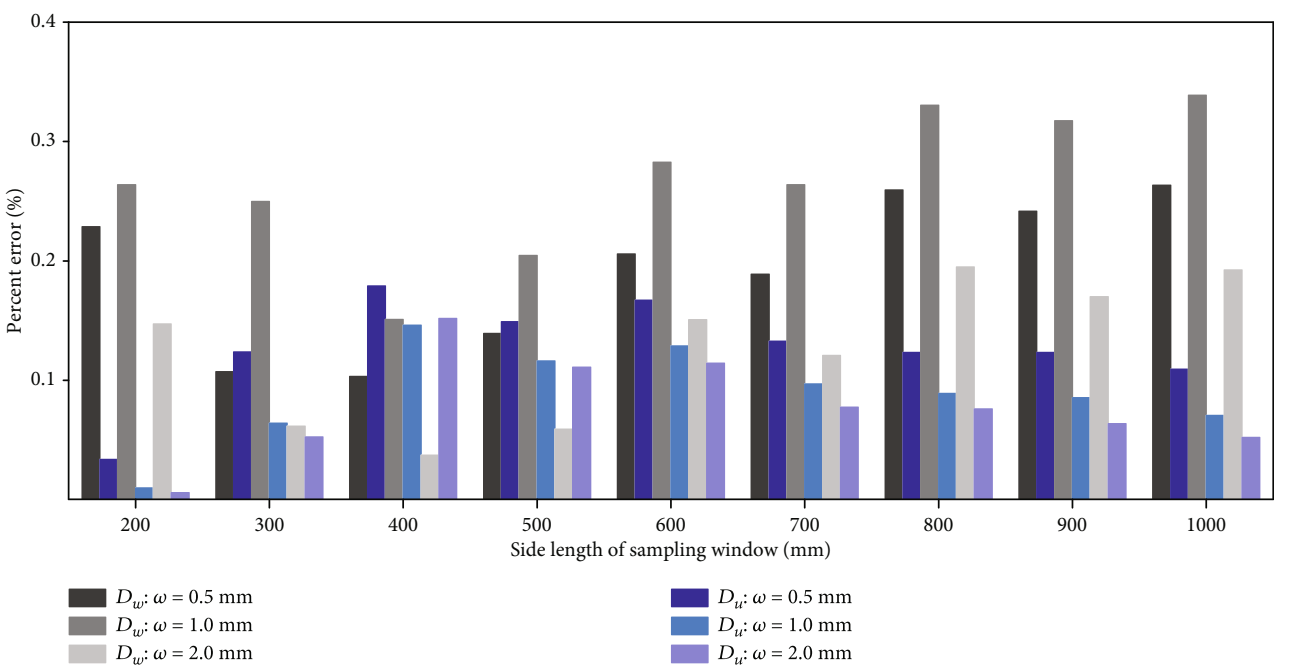

(a) Percent errors of fractal dimensions of waviness and unevenness of joint sample $S_{1}$

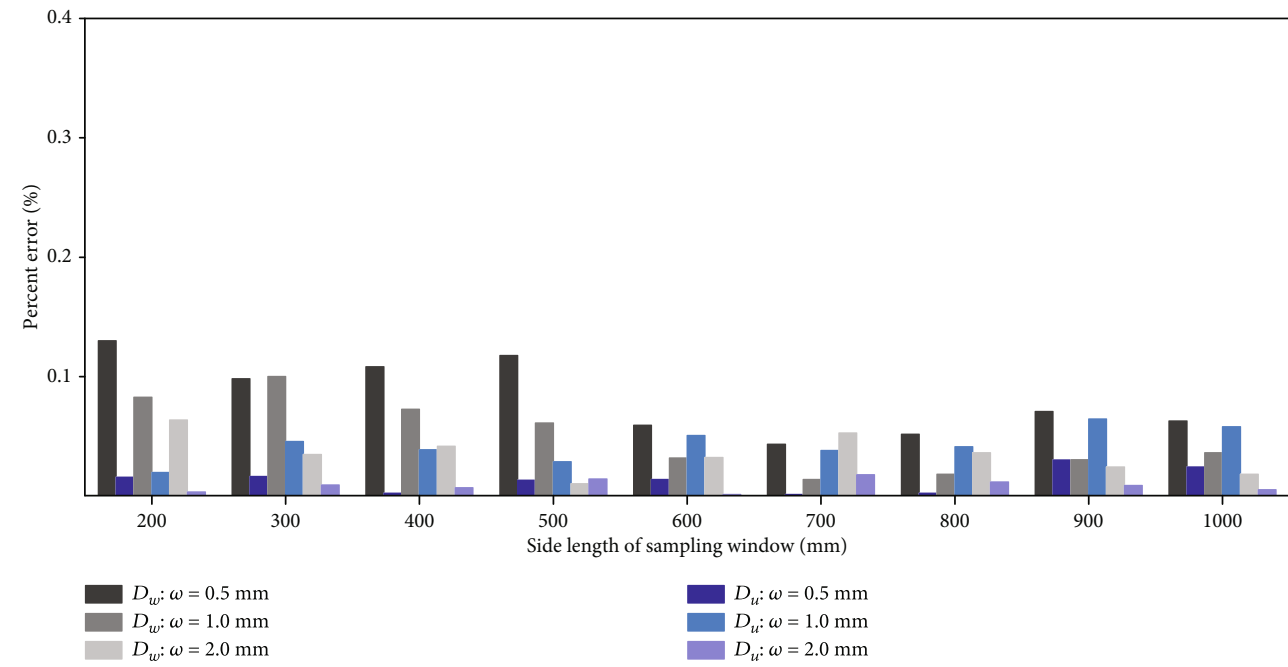

(b) Percent errors of fractal dimensions of waviness and unevenness of joint sample $S_{2}$

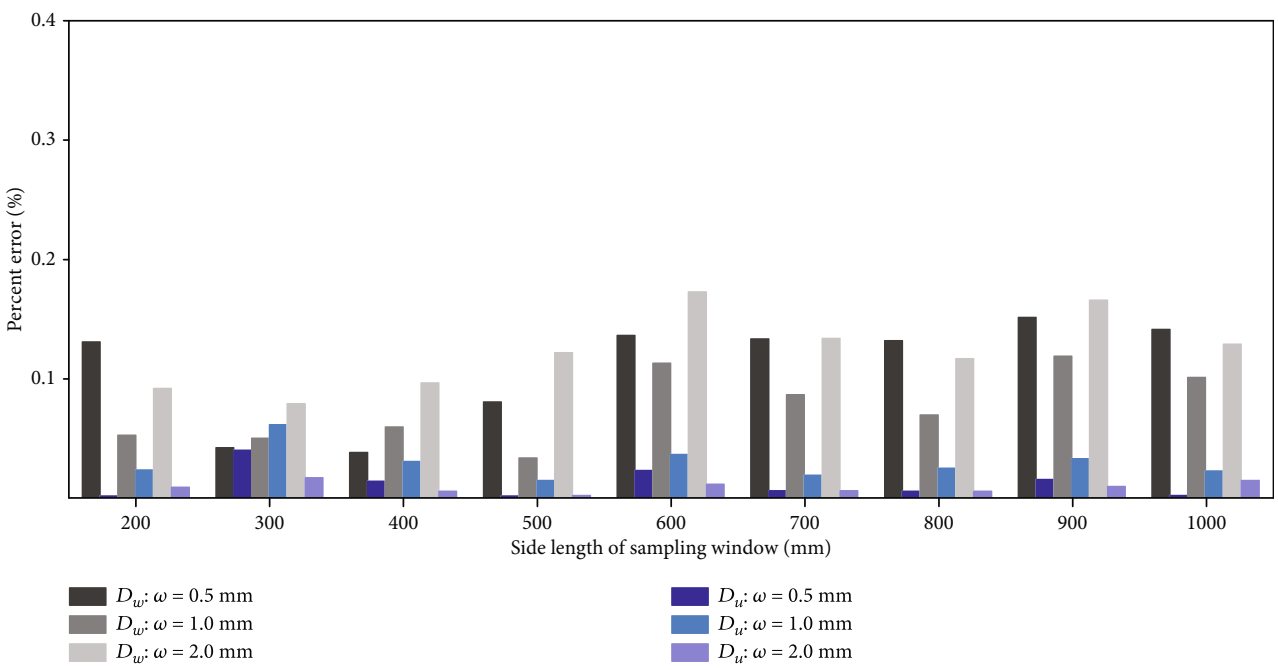

(c) Percent errors of fractal dimensions of waviness and unevenness of joint sample $S_{3}$

Figure 8: Effect of window size on the fractal dimensions of waviness and unevenness of three rock joints of three resolutions. Percent errors are relative to the values of window size of $100 \mathrm{~mm} \times 100 \mathrm{~mm} . D_{w}$ and $D_{u}$ are fractal dimensions of waviness and unevenness. $\omega$ denotes the point spacing. 


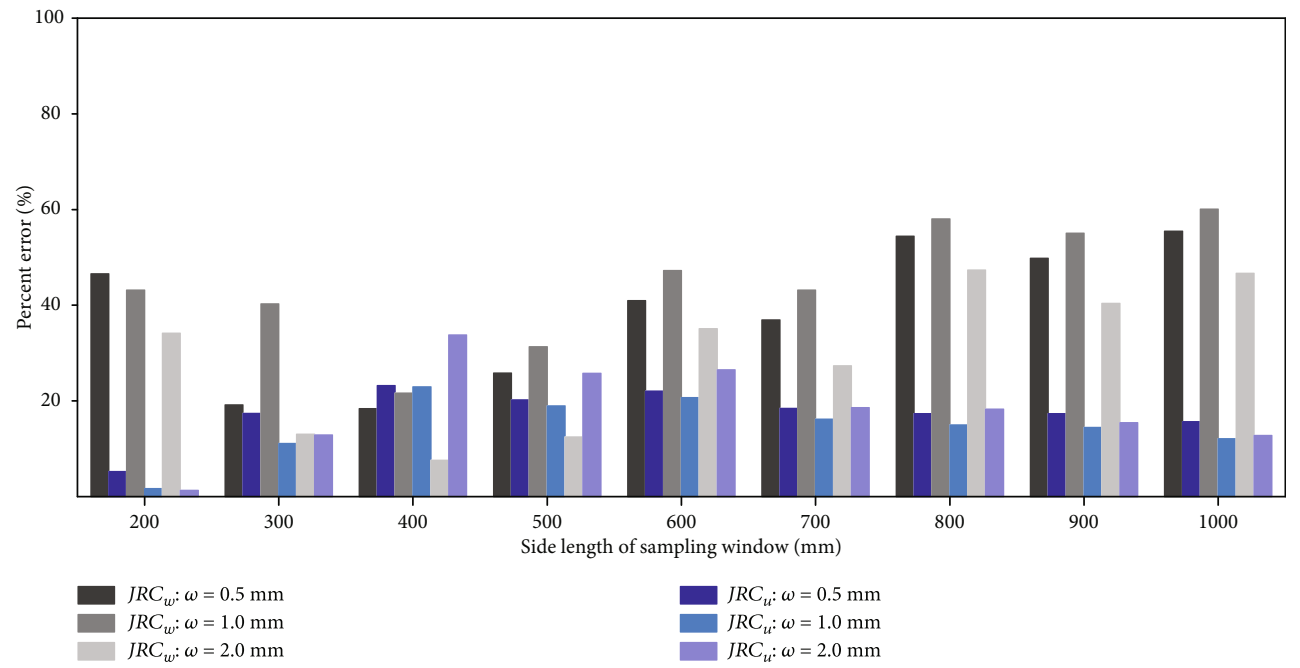

(a) Percent errors of the $J R C$ values of waviness and unevenness of joint sample $S_{1}$

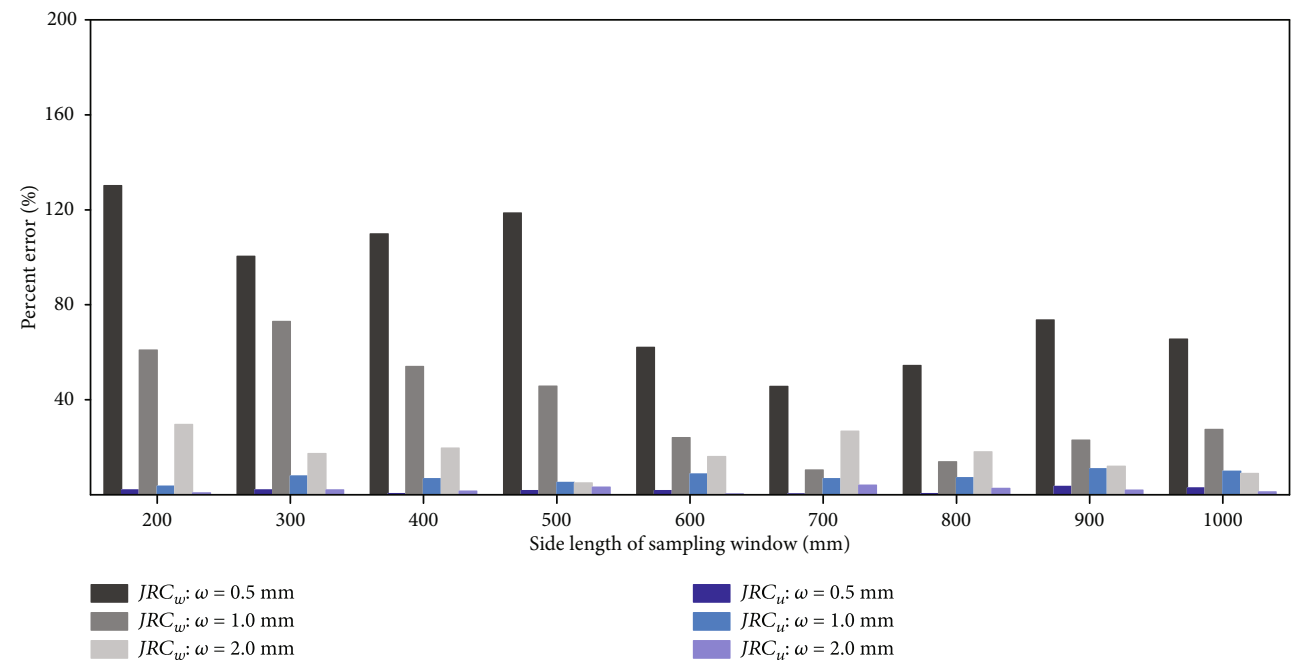

(b) Percent errors of the $J R C$ values of waviness and unevenness of joint sample $S_{2}$

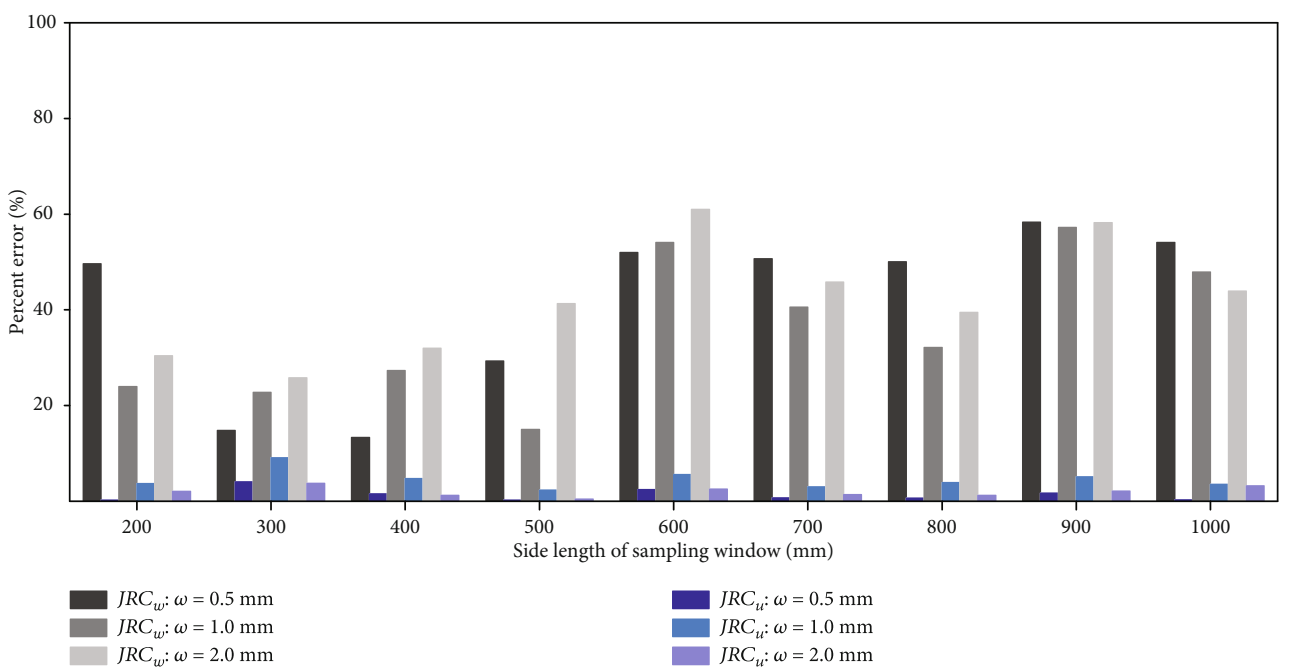

(c) Percent errors of the $J R C$ values of waviness and unevenness of joint sample $S_{3}$

Figure 9: Effect of window size on the $J R C$ values of waviness and unevenness of three rock joints of three resolutions. Percent errors are relative to the values of window size of $100 \mathrm{~mm} \times 100 \mathrm{~mm} . J R C_{w}$ and $J R C_{u}$ are the $J R C$ values of waviness and unevenness, respectively. $\omega$ denotes the point spacing. 


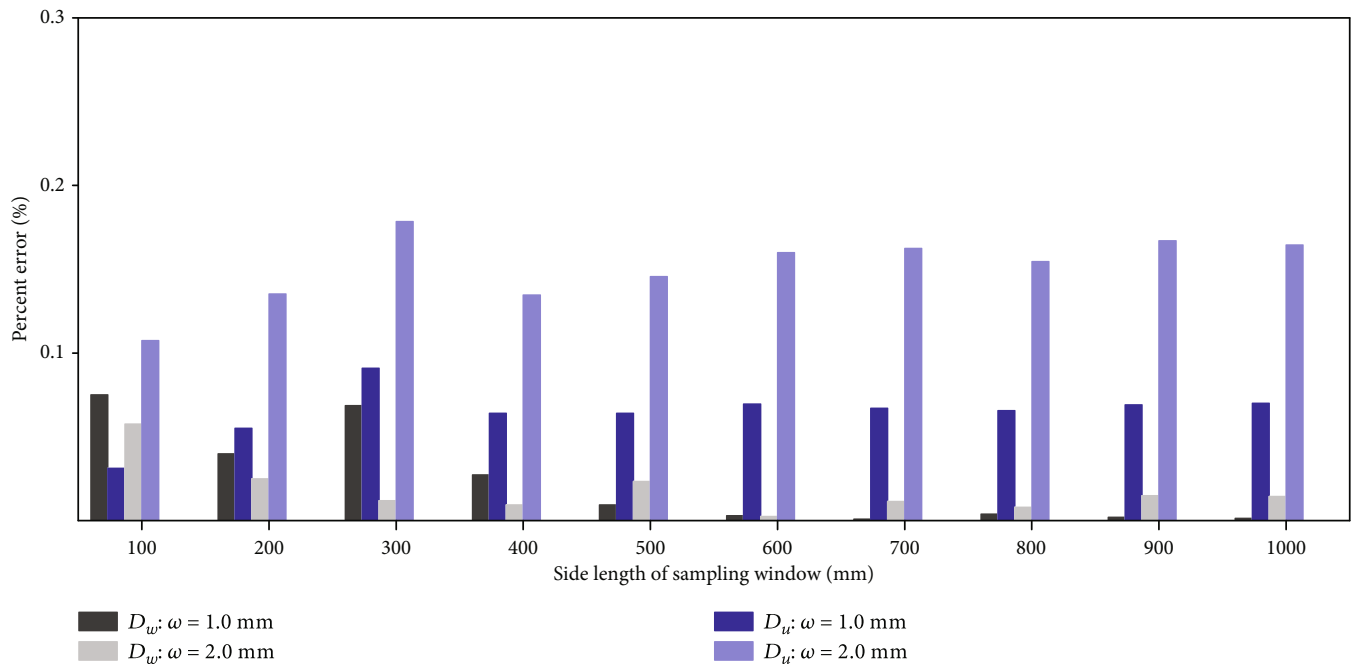

(a) Percent errors of fractal dimensions of waviness and unevenness of joint sample $S_{1}$

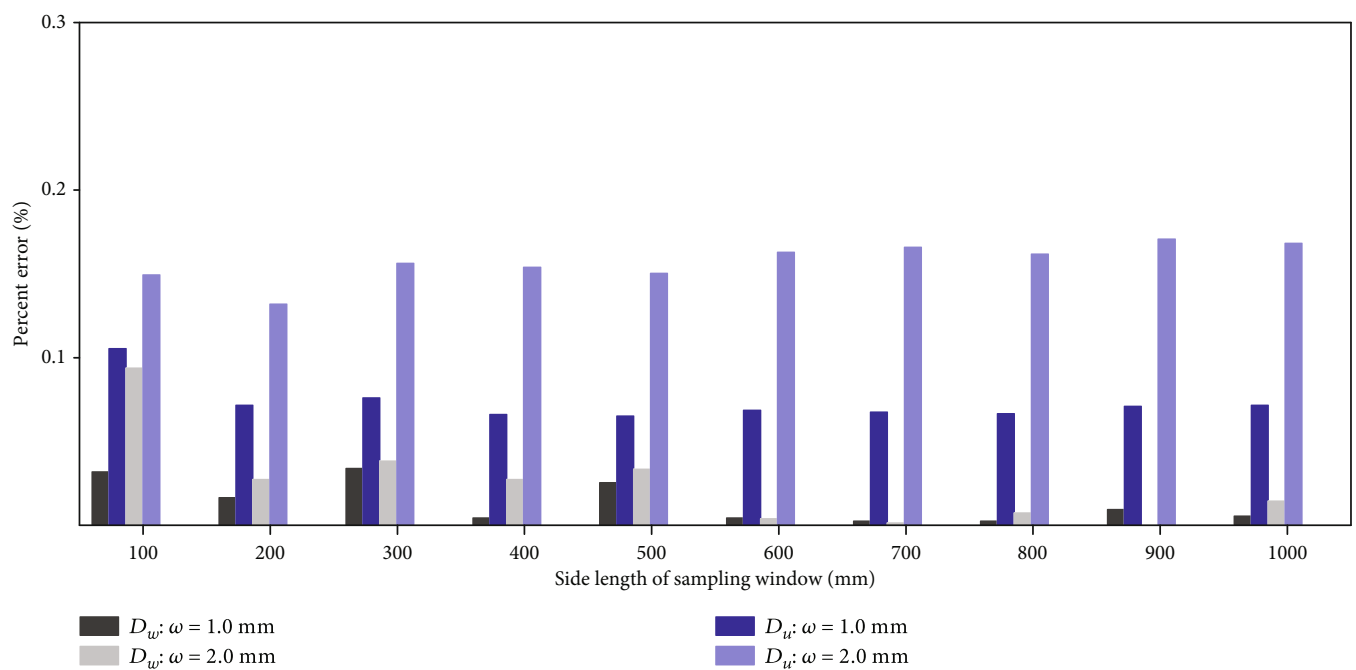

(b) Percent errors of fractal dimensions of waviness and unevenness of joint sample $S_{2}$

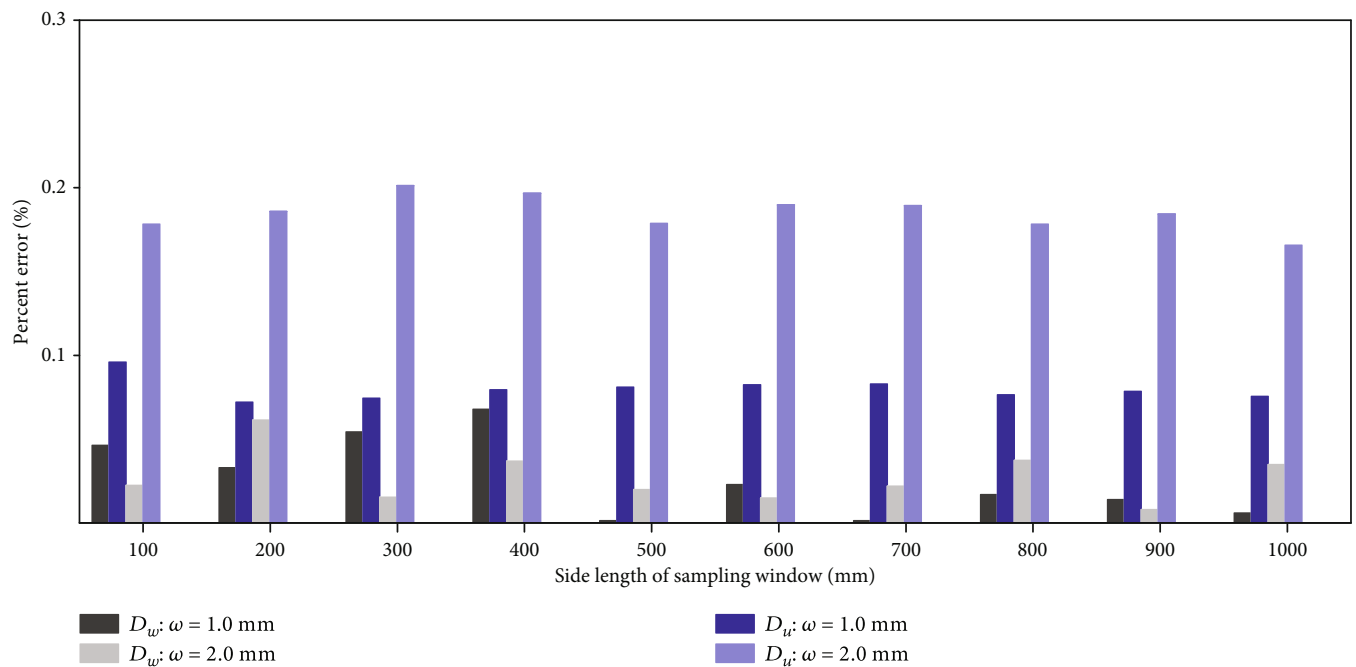

(c) Percent errors of fractal dimensions of waviness and unevenness of joint sample $S_{3}$

FIGURE 10: Effect of resolution on the fractal dimensions of waviness and unevenness of three rock joints of varying sampling window sizes. Percent errors are calculated relative to the values of resolution of $0.5 \mathrm{~mm} . D_{w}$ and $D_{u}$ are fractal dimensions of waviness and unevenness, respectively. $\omega$ denotes the point spacing. 


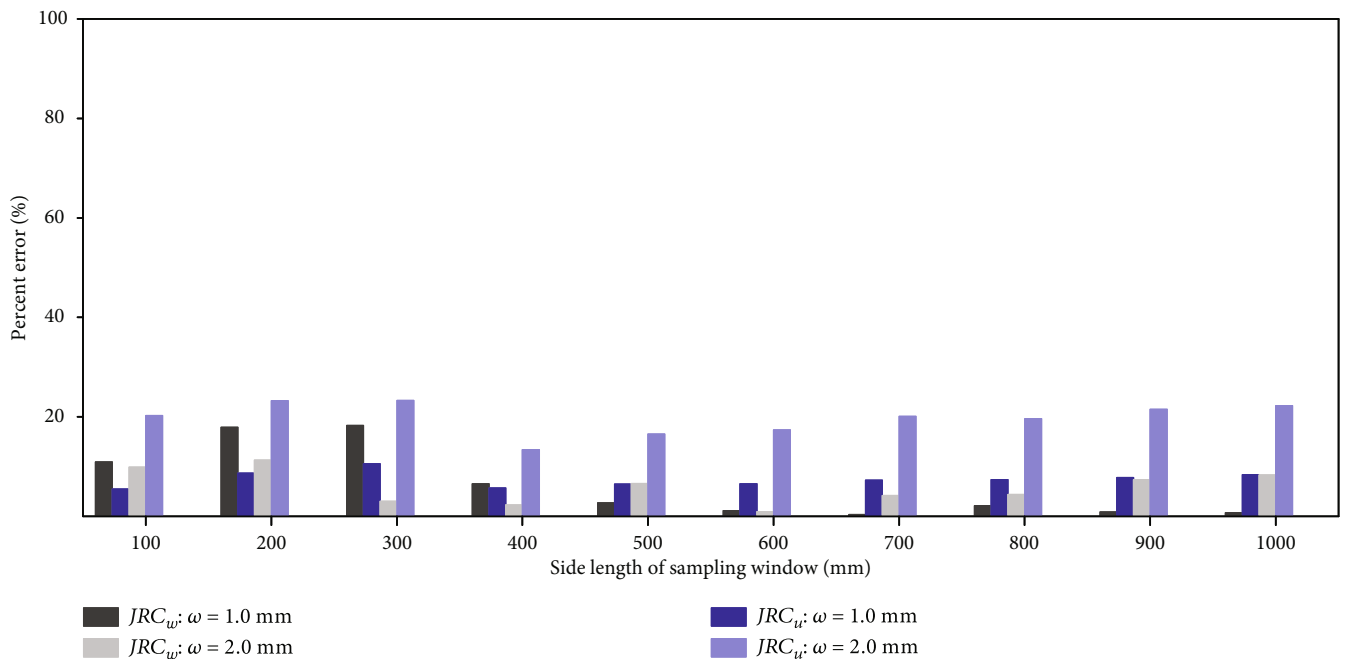

(a) Percent errors of the $J R C$ values of waviness and unevenness of joint sample $S_{1}$

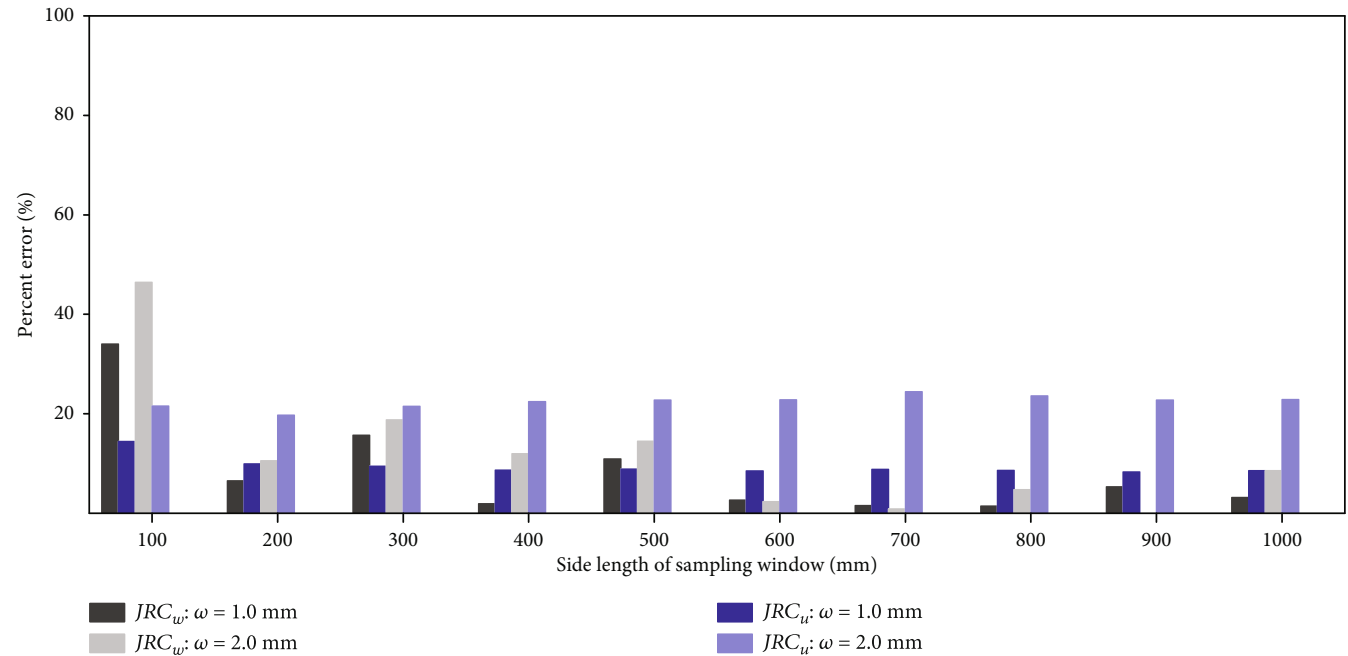

(b) Percent errors of the $J R C$ values of waviness and unevenness of joint sample $S_{2}$

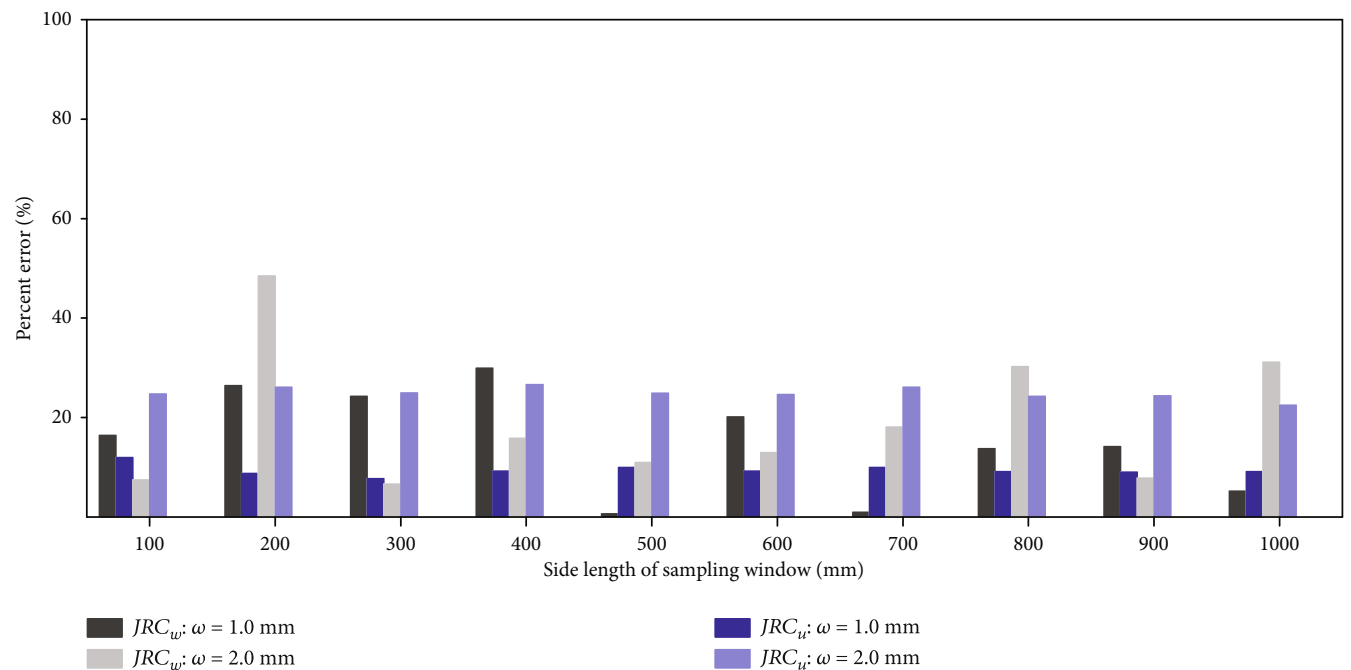

(c) Percent errors of the $J R C$ values of waviness and unevenness of joint sample $S_{3}$

FIGURE 11: Effect of resolution on the $J R C$ values of waviness and unevenness of three rock joint samples of varying sampling window sizes. Percent errors are calculated relative to the values of resolution of $0.5 \mathrm{~mm} . J R C_{w}$ and $J R C_{u}$ are the $J R C$ values of waviness and unevenness, respectively. $\omega$ denotes the point spacing. 


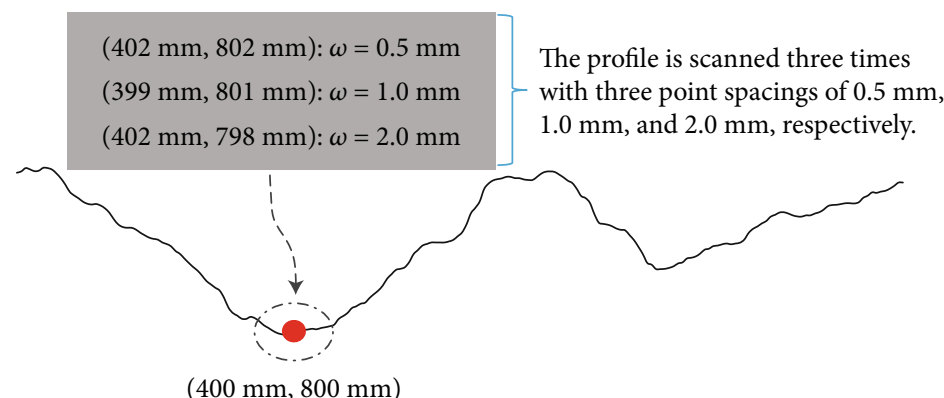

FIGURE 12: Illustration of the coordinate deviation due to manual operation.

dimension of waviness of the three samples is negligible (Figures 8 and 11). The minor discrepancies mainly originated from the fact that it is impossible to acquire exactly the same coordinates of a certain point due to the error caused by the manual operation of the HandyPROBE. For the example, in Figure 12, the coordinates $(400 \mathrm{~mm}$, $800 \mathrm{~mm}$ ) of a point of a profile are perhaps digitised as $(402 \mathrm{~mm}, 802 \mathrm{~mm}), \quad(399 \mathrm{~mm}, 801 \mathrm{~mm})$, and $(402 \mathrm{~mm}$, $798 \mathrm{~mm}$ ) during the scanning with point spacings of $0.5 \mathrm{~mm}, 1.0 \mathrm{~mm}$, and $2.0 \mathrm{~mm}$, respectively.

Figures 8 and 10 show that both window size and measurement resolution affect the fractal dimensions of waviness and unevenness. The measurement resolution has no less influence than window size on the variation of fractal dimension. Previous studies [18-23] have reported positive, negative, and no scale effects when large-scale rock joint surfaces are measured. The controversial results may be stemmed from the combinative effects of sample size and measurement resolution. Most of the studies on large-scale rock joints in the literature [21, 23, 47] used inconsistent measurement resolutions to digitise rock joint surfaces of varying scales. In these studies, the point spacing was increased as larger areas (or lengths) of the rock joint surface were examined. Therefore, the change in roughness with increased rock joint size reported in this work was also possibly a result of the varying measurement resolution besides the variation in roughness [22].

\section{Discussion and Implications}

We explored the fractal characteristics of two-order asperities of natural rock joints in window sizes from $100 \mathrm{~mm} \times 100 \mathrm{~mm}$ to $1000 \mathrm{~mm} \times 1000 \mathrm{~mm}$ with three different resolutions.

Both the fractal dimensions of waviness and unevenness vary as the window size increases.

Nevertheless, no apparent stationarity threshold has been found for the three natural granite joints. The findings contrast with the results reported in Fardin et al. [23]. Using the roughness length method [33], Fardin et al. [23] studied the fractal dimension of the surface roughness of a rock joint up to the window size of $1000 \mathrm{~mm} \times 1000 \mathrm{~mm}$.

They claimed that for sampling windows having a size larger than a stationarity threshold of roughly $500 \mathrm{~mm} \times$ $500 \mathrm{~mm}$, the fractal dimension remained almost unvaried and can be considered as reliable estimation. The discrepancy between Fardin et al. [23] and our study possibly resulted from the following reasons. First, a single fractal dimension, i.e., the fractal dimension of unevenness, was estimated by Fardin et al. [23]. In the calculation of the roughness length method, the local trend, the asperities with long wavelength (which is termed waviness in this study) are excluded to avoid overestimating roughness in small windows [32, 33]. Second, the fractal dimension of unevenness with relatively small and similar wavelength and amplitude probably keeps almost constant as the sampling data reaches a certain large volume since fractal dimension is essentially determined based on statistical consideration. For example, the fractal dimensions of unevenness of rock joint samples $S_{2}$ and $S_{3}$ in this study (Figures 7(b) and 7(c)) appear unchanged when the window size exceeds $400 \mathrm{~mm} \times 400 \mathrm{~mm}$. Moreover, the surface of merely one rock joint was studied by Fardin et al. [23], based on which affirmative conclusions cannot be drawn without examining the fractal features of several more large-scale rock joints with varying surface roughness.

Quantification of the surface roughness of a natural rock joint is critical for predicting the mechanical and hydraulic properties of a rock mass. Particularly, the shear behaviour of rock joints is strongly affected by surface roughness. Under a low normal stress (relative to rock strength), a rock joint fails in shear due to asperity dilation. In this case, both waviness and unevenness contribute to the degree of dilatancy. When the normal stress is high, joint shear behaviour is mainly controlled by the damage or degradation of waviness since unevenness is much more easily sheared off. The permeability of rock joints under shearing is closely associated with the dilation and degradation of asperities [48-53]. That is to say, waviness and unevenness of the surface roughness of a natural rock joint should be separately considered for accurately predicting the hydromechanical behaviour of a rock mass. Currently, surface roughness of rock joints at field scales is commonly evaluated from laboratory experimentation on small joint samples through scaling laws [18, 54]. These laws are unable to, respectively, take into account the variations of waviness and unevenness at different scales.

Additionally, our findings based on three natural rock joints sized $1000 \mathrm{~mm} \times 1000 \mathrm{~mm}$ show that the fractal dimensions of waviness and unevenness seemingly vary without a universal trend as the joint sample size changes. In other words, waviness and unevenness of rock joints should be quantified at the scales of rock masses in the field 
mainly due to the random nature of asperity distribution along a joint surface [55].

\section{Conclusions}

We investigated the scale effect of surface roughness of natural rock joints using fractal approach. Three natural granite joints dimensioned of $1000 \times 1000 \mathrm{~mm}$ were digitised and reconstructed at three different measurement resolutions. The fractal characteristics of two-order roughness, i.e., waviness and unevenness, were separately quantified through the classic triangular prism surface area method (TPM). We found that each-order roughness of a natural rock joint in window sizes varying from $100 \mathrm{~mm} \times 100 \mathrm{~mm}$ to $1000 \mathrm{~mm}$ $\times 1000 \mathrm{~mm}$ owns individual fractal dimension. Although both the fractal dimensions of waviness and unevenness are scale-dependent, no noticeable stationarity threshold of scale effect has been found primarily due to the randomness of roughness distribution. Additionally, the measurement resolution has remarkable influence on the fractal dimension of unevenness, whereas its effect on that of waviness is negligible. Surface roughness quantification plays a key role in predicting the hydromechanical behaviour of rock masses. Our findings suggest that waviness and unevenness should be separately characterised at the field scale of the rock mass with an appropriate consistent measurement resolution. The conclusions are drawn by examining three natural rock joints with the dimension up to $1000 \mathrm{~mm} \times 1000 \mathrm{~mm}$. The existence of a stationarity threshold of a larger value remains questionable due to the absence of experimental data. One may argue that the surface roughness of a natural rock joint likely exhibits more than two-order roughness.

However, roughness characterisation with two-order roughness is sufficient for the purpose of accurately estimating the mechanical and hydraulic properties of rock joints. Further studies are to investigate the anisotropy of the fractal features of surface roughness since the hydromechanical behaviours of rock joints are strongly direction-dependent.

\section{Data Availability}

The experimental data used to support the findings of this study are included within the article.

\section{Conflicts of Interest}

The authors declare they have no conflicts of interest to this work.

\section{Acknowledgments}

Yingchun Li thanks the financial support from the National Natural Science Foundation (51809033), the China Postdoctoral Science Foundation (2019T120208), the National Key Research and Development Plan (2018YFC1505301), and the Fundamental Research Funds for the Central Universities (DUT20LK15).

\section{References}

[1] B. Brady and E. Brown, Rock Mechanics for Underground Mining, Kluwer Academic Publishers, 2006.

[2] International Journal of Rock Mechanics and Mining Sciences, "Commission on standardization of laboratory and field tests of the international society for rock mechanics: 'suggested methods for the quantitative description of discontinuities', Int J Rock Mech Min, vol. 15, no. 6, pp. 320-368, 1978.

[3] F. Patton, Multiple failure modes of rock and related materials, [Ph.D. thesis], University of Illinois, 1966.

[4] Q. He, Y. Li, J. Xu, and C. Zhang, "Prediction of mechanical properties of igneous rocks under combined compression and shear loading through statistical analysis," Rock Mechanics and Rock Engineering, vol. 53, no. 2, pp. 841-859, 2020.

[5] L. Jing, E. Nordlund, and O. Stephansson, “An experimental study on the anisotropy and stress-dependency of the strength and deformability of rock joints," International Journal of Rock Mechanics and Mining Sciences \& Geomechanics Abstracts, vol. 29, no. 6, pp. 535-542, 1992.

[6] H. Lee, Y. Park, T. Cho, and K. You, "Influence of asperity degradation on the mechanical behavior of rough rock joints under cyclic shear loading," International Journal of Rock Mechanics and Mining Sciences, vol. 38, no. 7, pp. 967-980, 2001.

[7] Y. Li, J. Oh, R. Mitra, and B. Hebblewhite, "A constitutive model for a laboratory rock joint with multi-scale asperity degradation," Computers and Geotechnics, vol. 72, pp. 143-151, 2016.

[8] Z. Yang, C. Di, and K. Yen, "The effect of asperity order on the roughness of rock joints," International Journal of Rock Mechanics and Mining Sciences, vol. 38, no. 5, pp. 745-752, 2001.

[9] Y. Li, J. Oh, R. Mitra, and I. Canbulat, "A fractal model for the shear behaviour of large-scale opened rock joints," Rock Mechanics and Rock Engineering, vol. 50, no. 1, pp. 67-79, 2017.

[10] N. Barton and V. Choubey, "The shear strength of rock joints in theory and practice," Rock Mechanics, vol. 10, no. 1-2, pp. 154, 1977.

[11] H. Dong, G. Poropat, I. Gratchev, and A. Balasubramaniam, "Improvement of photogrammetric JRC data distributions based on parabolic error models," International Journal of Rock Mechanics and Mining Sciences, vol. 80, pp. 19-30, 2015.

[12] Y. Li, C. Tang, D. Li, and C. Wu, "A new shear strength criterion of three-dimensional rock joints," Rock Mechanics and Rock Engineering, vol. 53, no. 3, pp. 1477-1483, 2020.

[13] G. Morelli, "On joint roughness: measurements and use in rock mass characterization," Geotechnical and Geological Engineering, vol. 32, no. 2, pp. 345-362, 2014.

[14] R. Tse and D. Cruden, "Estimating joint roughness coefficients," International Journal of Rock Mechanics and Mining Sciences \& Geomechanics Abstracts, vol. 16, no. 5, pp. 303307, 1979.

[15] X. Yu and B. Vayssade, "Joint profiles and their roughness parameters," International Journal of Rock Mechanics and Mining Sciences \& Geomechanics Abstracts, vol. 28, no. 4, pp. 333-336, 1991.

[16] Y. Li, S. Sun, and C. Tang, "Analytical prediction of the shear behaviour of rock joints with quantified waviness and unevenness through wavelet analysis," Rock Mechanics and Rock Engineering, vol. 410, pp. 1-13, 2019. 
[17] L. Zou, L. Jing, and V. Cvetkovic, "Roughness decomposition and nonlinear fluid flow in a single rock fracture," International Journal of Rock Mechanics and Mining Sciences, vol. 75, pp. 102-118, 2015.

[18] S. Bandis, A. Lumsden, and N. Barton, "Experimental studies of scale effects on the shear behaviour of rock joints," International Journal of Rock Mechanics and Mining Sciences \& Geomechanics Abstracts, vol. 18, no. 1, pp. 1-21, 1981.

[19] M. Cravero, G. Iabichino, and V. Piovano, "Analysis of large joint profiles related to rock slope instabilities," in Proceedings of the 8th ISRM Congress, pp. 423-428, Tokyo, Japan, 1995.

[20] N. Fardin, "Influence of structural non-stationarity of surface roughness on morphological characterization and mechanical deformation of rock joints," Rock Mechanics and Rock Engineering, vol. 41, no. 2, pp. 267-297, 2008.

[21] N. Maerz and J. Franklin, "Roughness scale effects and fractal dimension," in Proceedings of the First International Workshop on Scale Effects in Rock Masses, pp. 121-125, Loen, Norway, 1990.

[22] B. Tatone and G. Grasselli, "An investigation of discontinuity roughness scale dependency using high-resolution surface measurements," Rock Mechanics and Rock Engineering, vol. 46, no. 4, pp. 657-681, 2013.

[23] N. Fardin, O. Stephansson, and L. Jing, "The scale dependence of rock joint surface roughness," International Journal of Rock Mechanics and Mining Sciences, vol. 38, no. 5, pp. 659-669, 2001.

[24] B. Mandelbrot, "How long is the coast of Britain? Statistical self-similarity and fractional dimension," Science, vol. 156, no. 3775, pp. 636-638, 1967.

[25] B. Mandelbrot, "Self-affine fractals and fractal dimension," Physica Scripta, vol. 32, no. 4, pp. 257-260, 1985.

[26] Y. Lee, J. Carr, D. Barr, and C. Haas, "The fractal dimension as a measure of the roughness of rock discontinuity profiles," International Journal of Rock Mechanics and Mining Sciences \& Geomechanics Abstracts, vol. 27, no. 6, pp. 453-464, 1990.

[27] L. Liebovitch and T. Toth, "A fast algorithm to determine fractal dimensions by box counting," Physics Letters A, vol. 141, no. 8-9, pp. 386-390, 1989.

[28] P. Kulatilake, P. Balasingam, J. Park, and R. Morgan, "Natural rock joint roughness quantification through fractal techniques," Geotechnical and Geological Engineering, vol. 24, no. 5, pp. 1181-1202, 2006.

[29] M. Kwasniewski and J. Wang, "Application of laser profilometry and fractal analysis to measurement and characterization of morphological features of rock fracture surfaces," in Geotechnique et Environnement, Colloque Franco-Polonais, pp. 163-176, CRC Press, Balkema, Rotterdam, 1993.

[30] S. Brown, "A Note on the description of surface roughness using fractal dimension," Geophysical Research Letters, vol. 14, no. 11, pp. 1095-1098, 1987.

[31] H. Yang, B. Baudet, and T. Yao, "Characterization of the surface roughness of sand particles using an advanced fractal approach," Proceedings of the Royal Society A: Mathematical, Physical and Engineering Sciences, vol. 472, no. 2194, article 20160524, 2016.

[32] P. H. S. W. Kulatilake, J. Um, and G. Pan, "Requirements for accurate quantification of self-affine roughness using the variogram method," International Journal of Solids and Structures, vol. 35, no. 31-32, pp. 4167-4189, 1998.
[33] A. Malinverno, "A simple method to estimate the fractal dimension of a self-affine series," Geophysical Research Letters, vol. 17, no. 11, pp. 1953-1956, 1990.

[34] M. Matsushita and S. Ouchi, "On the self-affinity of various curves," Physica D, vol. 38, no. 1-3, pp. 246-251, 1989.

[35] K. C. Clarke, "Computation of the fractal dimension of topographic surfaces using the triangular prism surface area method," Computers \& Geosciences, vol. 12, no. 5, pp. 713$722,1986$.

[36] W. Ju and S. Lam, "An improved algorithm for computing local fractal dimension using the triangular prism method," Computers \& Geosciences, vol. 35, no. 6, pp. 1224-1233, 2009.

[37] D. Santis, M. Fedi, and T. Quarta, “A revisitation of the triangular prism surface area method for estimating the fractal dimension of fractal surfaces," Annals of Geophysics, vol. 40, no. 4, 1997.

[38] Y. Jiang, B. Li, and Y. Tanabashi, "Estimating the relation between surface roughness and mechanical properties of rock joints," International Journal of Rock Mechanics and Mining Sciences, vol. 43, no. 6, pp. 837-846, 2006.

[39] H. Xie, J. Wang, and M. Kwasniewski, "Multifractal characterization of rock fracture surfaces," International Journal of Rock Mechanics and Mining Sciences, vol. 36, no. 1, pp. 19-27, 1999.

[40] H. Xie and J. Wang, "Direct fractal measurement of fracture surfaces," International Journal of Solids and Structures, vol. 36, no. 20, pp. 3073-3084, 1999.

[41] H. Zhou and H. Xie, "Direct estimation of the fractal dimensions of a fracture surface of rock," Surface Review and Letters, vol. 10, no. 5, pp. 751-762, 2003.

[42] N. Lam, H. Qiu, D. Quattrochi, and C. Emerson, "An evaluation of fractal methods for characterizing image complexity," Cartography and Geographic Information Science, vol. 29, no. 1, pp. 25-35, 2002.

[43] S. Jaggi, D. A. Quattrochi, and N. S.-N. Lam, "Implementation and operation of three fractal measurement algorithms for analysis of remote-sensing data," Computers \& Geosciences, vol. 19, no. 6, pp. 745-767, 1993.

[44] M. Sakellariou, B. Nakos, and C. Mitsakaki, "On the fractal character of rock surfaces," International Journal of Rock Mechanics and Mining Sciences \& Geomechanics Abstracts, vol. 28, no. 6, pp. 527-533, 1991.

[45] Y. Li and R. Huang, "Relationship between joint roughness coefficient and fractal dimension of rock fracture surfaces," International Journal of Rock Mechanics and Mining Sciences, vol. 75, pp. 15-22, 2015.

[46] Y. Li, A consitutive model of opened rock joints in the field, [Ph.D. thesis], University of New South Wales, Sydney, 2016.

[47] M. Cravero, G. Iabichino, and A. Ferrero, "Evaluation of joint roughness and dilatancy of schistosity joints," in Proceedings of Eurock 2001:Rock Mechanics-a Challenge for Society, pp. 217222, Espoo, Finland, 2001.

[48] N. Huang, R. Liu, and Y. Jiang, "Numerical study of the geometrical and hydraulic characteristics of 3D self-affine rough fractures during shear," Journal of Natural Gas Science and Engineering, vol. 45, pp. 127-142, 2017.

[49] B. Li, Y. Jiang, T. Koyama, L. Jing, and Y. Tanabashi, "Experimental study of the hydro-mechanical behavior of rock joints using a parallel-plate model containing contact areas and artificial fractures," International Journal of Rock Mechanics and Mining Sciences, vol. 45, no. 3, pp. 362375, 2008. 
[50] R. Liu, Y. Jiang, B. Li, and X. Wang, "A fractal model for characterizing fluid flow in fractured rock masses based on randomly distributed rock fracture networks," Computers and Geotechnics, vol. 65, pp. 45-55, 2015.

[51] R. Liu, B. Li, and Y. Jiang, "A fractal model based on a new governing equation of fluid flow in fractures for characterizing hydraulic properties of rock fracture networks," Computers and Geotechnics, vol. 75, pp. 57-68, 2016.

[52] X. Xiong, B. Li, Y. Jiang, T. Koyama, and C. Zhang, "Experimental and numerical study of the geometrical and hydraulic characteristics of a single rock fracture during shear," International Journal of Rock Mechanics and Mining Sciences, vol. 48, no. 8, pp. 1292-1302, 2011.

[53] Y. Li, C. Wu, and B. Jang, "Effect of bedding plane on the permeability evolution of typical sedimentary rocks under triaxial compression," Rock Mechanics and Rock Engineering, 2020.

[54] J. Oh, E. Cording, and T. Moon, "A joint shear model incorporating small-scale and large-scale irregularities," International Journal of Rock Mechanics and Mining Sciences, vol. 76, pp. 78-87, 2015.

[55] S. Hencher and L. Richards, "Assessing the shear strength of rock discontinuities at laboratory and field scales," Rock Mechanics and Rock Engineering, vol. 48, no. 3, pp. 883-905, 2015. 